\title{
Cristología latinoamericana: Bibliografía (1968-2000)
}

Determinar qué sea la "cristología latinoamericana" constituye un problema teológico en sí mismo. La elaboración de la bibliografía de la cristología latinoamericana supone una clarificación del problema anterior. Mientras esto no se haga, la bibliografía que ofrecemos no puede sino ser lo más amplia posible. Esperamos que su publicación contribuya al discernimiento teológico en cuestión.

$\mathrm{Al}$ efecto nos regimos por los siguientes criterios formales. Ponemos como fecha de inicio el año 1968, dado que la Conferencia Episcopal de Medellín marca un hito en la historia de la teología latinoamericana. Hemos procurado asegurar que incluimos todo lo publicado hasta el año 2000, aunque también reportamos algunas publicaciones posteriores. ¿Qué autores? ¿Qué títulos? Trátese de libros o artículos, hemos optado por los autores que hayan nacido o se hayan arraigado en América Latina, o bien que hayan publicado en nuestro continente. A veces hemos considerado a algunos extranjeros que han publicado algo importante sobre esta materia en otras partes.

Para recopilar la información hemos recurrido a dos fuentes principales: al SELADOC (Servicio Latinoamericano de Documentación de la Facultad de Teología de la Pontificia Universidad Católica de Chile (PUC), que ha indexado por largos años los artículos de las principales revistas teológicas latinoamericanas) y a la obra en cuatro tomos de Antonio Bentué (Ed.) L'Església que és a Amèrica. Literatura teològica Llatinoamericana, Facultat de Teologia de Catalunya, 1968-2000.

Esta bibliografia ha sido elaborada con la colaboración de los alumnos del curso de Cristología Latinoamericana de los años 2002 y 2003 de la PUC, y la ayuda particular de Jimena Mason.

\section{LIBROS}

AA.VV. La lucha de los dioses. Los ídolos de la opresión y la búsqueda del Dios liberador, San José, 1980.

AA.VV, Jesús. Cuestiones sobre cristología, Arquediócesis de Medellín, 1983.

AA.VV. El misterio de la Trinidad en la preparación del gran jubileo, San Pablo, Buenos Aires, 1998. 
ACO Jesus: sua terra, seu povo, sua proposta, ACO, São Paulo, 1982, 108 pp.

ALlGAYER, António Jesús e os excluidos do Reino, Vozes, Petrópolis, 1994, 128 pp.

ALVAREZ, Miguel Jesús de Candelaria en la historia, el arte y la tradición de Guatemala, Consejo Nacional para la Protección de la Antigua Guatemala, Guatemala, 1983, $121 \mathrm{pp}$.

ANDRADE TANNUS, Roberto Curados e restaurados por Jesus, Santuário, Aparecida, 1997, 165 pp.

ANTONIAZZI, Alberto Anunciar à Jesus Cristo: Como? Fascículo de la Revista de Estudios Bíblicos dedicado al tema del Kerigma, 1993, 88 pp.

ALARCO, Luis Felipe Jesús ante la muerte, Universidad Mayor de San Marcos, Lima, 1981, 723 pp.

ALLIENDE, Joaquín Jesús de Nazaret, Patris, Santiago, 1996.

ALMEIDA, Lucas de Paula Quem é Jesus Cristo? Vol. I: Sua infância e vida oculta, O Lutador, Belo Horizonte, 1999, 316 pp.

ALT, Franz Jesús, el primer hombre nuevo, El Almendro, Córdoba, 1993, 173 pp.

ARENS, Eduardo La Trinidad, experiencia de comunión, CEP, Lima, 2000, $117 \mathrm{pp}$

ARENS, Eduardo ¿Resucitó? Una mirada crítica al fundamento del cristianismo, San Pablo, Santiago, 1993, 159 pp.

ARGÜELLO, José Un pobre Jesús, Hispamer, Managua, 2000, 501 pp.

ARIAS, Maximino Jesús el Cristo, Madrid, 1983.

ARIAS, M., GONZÁLEZ, C.I. y CONTRERAS, E. La cristología en el contexto de la Nueva Evangelización, San Pablo, Santiago, 1993.

ARIAS, Mortimer Venga tu reino. La memoria subversiva de Jesús, CUPSA, México, 1980, 168 pp.

AUGUSTINOVICH, Agustín Jesús y la política, Caracas, 1973, 248 pp.

BARBIT, Pierre La pasión de Nuestro Señor Jesucristo vista por un cirujano, Promesa, México, 1984, 216 pp.

BARREIRO, Alvaro Os pobres e o reino: do Evangelho a João Paulo II, Loyola, São Paulo, 1983, 157 pp.

BARRETO, Angelo Dantas O anúncio do reino de Deus, Vozes, Petrópolis, 1974.

BATLLE, Agustín Jesús presente hoy, Comunidad Teológica Evangélica, 1978, 178 pp.

BATSTONE, David From Conquest to Struggle: Jesus of Nazareth in Latin America, State University of New York, 1991, 224 pp.

BAZARRA, Carlos La Santísima Trinidad. Oscuridad amable, San Pablo, Caracas, 2000, $112 \mathrm{pp}$.

BEASLEY, Murray ;Ha resucitado!, Bautista, El paso, 1973, 48 pp.

BELAÚNDE, Víctor Andrés El Cristo de la fe y los cristos literarios, Universidad Católica, Lima, 1993, 188 pp.

BELO, F. Lectura materialista de Marcos, Verbo Divino, Estela, 1975.

BENETTI, Santos Jesús y la vida nueva, Buenos Aires, Paulinas, 1973, 104 pp.

BENETTI, Santos Jesús y el cambio social, Ediciones Lohlé-Lumen, Buenos Aires, 1998, 119 pp.

BENETTI, Santos Jesús y su proyecto político, Lumen, Buenos Aires, 1998, 128 pp. 
BERMÚDEZ, Fernando Cristo muere y resucita en Guatemala, CUPSA, México, 1985, 68 pp.

BERGER, Klaus Qumram e Jesus, Vozes, Petrópolis, 1994, 120 pp.

BINGEMER, M.C y GALDINO FELLER, V. Deus Trinidade: a vida no coração do mondo, Livros básicos de teologia, Valencia, 2002, 174 pp.

BOCK, Valéria (i altres) Pedagogia de Jesus, Sinodal, São Paulo, 1988, 59 pp.

BOFF, L. Jesucristo el Liberador: ensayo cristológico para nuestro tiempo, Latinoamérica Libros, Buenos Aires, 1974.

BOFF, L. El Padrenuestro. La oración de la liberación integral, Paulinas, Madrid, 1982.

BOFF, L. Encarnação: A humanidade e ha jovialidade de Nosso Deus, Vozes, Petrópolis, 1977.

BOFF, L. Jesucristo y nuestro futuro de liberación, Indo American Press Service, Bogotá, 1978, 61 pp.

BOFF, Leonardo Jesucristo y la liberación del hombre, Cristiandad, Madrid, 1981, 661 pp. Incluye los siguientes trabajos:

Una cristología desde la periferia, $26 \mathrm{pp}$.

Jesucristo, liberador. Ensayo de cristología crítica para nuestro tiempo, 243 pp.

Pasión de Cristo y sufrimiento humano, 160 pp.

La resurrección de Cristo y nuestra resurrección, pp. 90.

El seguimiento de Cristo, $28 \mathrm{pp}$.

El Evangelio del Cristo cósmico, 84 pp.

BOFF, Leonardo Paixão de Cristo, paixão do mundo. Os fatos, as interpretaçôes e o significado ontem e hoje, Petropolis, 1977.

BOFF, L. Ressurreição de Cristo e nossa ressurreição na morte, Vozes, Petrópolis, 1977.

BOFF, L. La Trinidad, la Sociedad y la Liberación, Paulinas, Madrid, 1987.

BOFF, L. La Santísima Trinidad es la mejor comunidad, Paulinos, Bogotá, 1992, 186 pp.

BOFF, L. Cómo predicar la cruz hoy en una sociedad de crucificados?, IndoAmerican Press Service-Editores, Chapinero, Colombia, 1987, 42 pp.

BONINO, J.M. et al. Jesús: ni vencido ni monarca celestial, Buenos Aires, 1977.

BORGES HACKMANN, Geraldo Luiz Jesus Cristo, nosso Redentor, Edipucrs, Porto Alegre, 1997, 215 pp.

BRAVO, Carlos Jesús, hombre en conflicto. El relato de Marcos en América Latina, Sal Terrae, Santander, 1986, 310 pp.

BRAVO, Carlos Galilea, año 30. Historia de un conflicto. Para leer el evangelio de Marcos, Centro de reflexión teológica, México, 1989, 171 pp.

BRAVO, CATAO, COMBLIN et al. Cristología y Pastoral en América Latina, Ed. Terra Nova, Barcelona, 1966.

BRITO, Emilio Cristologia en América Latina, Loyola, São Paulo, 1983, $328 \mathrm{pp}$.

BRUGNARA, Roque A boa nova de Jesus Cristo, FTD, 1995, 142 pp.

BUSSMANN, C. Befreiung duch Jesus? Die Christologie der lateinamerikanischen Befreiungstheologie, München, 1980.

CAJIAO, J. Jesucristo y el Reino de Dios, Bogotá, 1985. 
CAMARGO, J.A. y CHÁVEZ, R. Jesucristo, sus dos pasiones, Paulinas, Buenos Aires, 1996, 200 pp.

CAMBON, E et al. O Deus de Jesus Cristo (curso de Teología/2), São Paulo, 1984.

CAMBON, E. Vivir la Trinidad. Pistas para una nueva sociedad, Ciudad Nueva, Buenos Aires, 1998.

CAMBON, E. La Trinidad modelo social, Editorial Ciudad Nueva, Madrid, 2000, 198 pp.

CAMPOS, E. Quem é este Homem condenado?, Petrópolis, Vozes, 1975, 26 pp.

CANTALAMESSA, Raniero Jesucristo, el Santo de Dios, Lumen, Buenos Aires, 1995, $207 \mathrm{pp}$.

CAPO, Jesús El Hijo del carpintero, Santiago, Grijalbo, 1996, 462 pp.

CARAVIAS, José Luis O Deus de Jesus, Vozes, Petrópolis, 1987, 175 pp.

CÁRDENAS, José El poder de Jesús el carpintero, CUPSA, México, 1983, $141 \mathrm{pp}$

CÁRDENAS, José Jesús, un pueblerino inquietante. Comentario al evangelio según san Marcos, Apóstoles de la Palabra, México, 1990, 128 pp.

CÁRDENAS, José Seguir al fichado Jesús. El llamamiento irresistible de Jesús en el Evangelio de San Marcos, Casa Unida de Publicaciones, México, 1989, $114 \mathrm{pp}$.

CÁRDENAS PALLARÉS, Raniero Por seguir a Jesús. El seguimiento en San Lucas, Dabar, México, 1997, 197 pp.

CÁRDENAS PALLARÉS, José Deshonra y triunfo de Jesús el Justo, Dabar, México, 1993, 120 pp.

CASTELLÁN, Leonardo Las parábolas de Cristo, Jauja, 1994, 352 pp.

CASTELLANI, Leonardo Cristo ¿vuelve o no vuelve?, Buenos Aires, Dictio, 1976, 300 pp.

CASTILlO, J.M. y ESTRADA, J.A. El proyecto de Jesús, Sígueme, Salamanca, 1985.

CASTILLO, J.M. El seguimiento de Jesús, Salamanca, 1986.

CELADEC, Jesús de Nazaret, CELADEC, Lima, 1982, 42 pp.

CELAM, Cristo el Señor, 1984

CELAM Textos inspirados sobre la Santa Trinidad, Celam, Bogotá, 1999, 109 pp.

CEP, Jesús ante la opresión, CEP, Lima, 1978, 136 pp.

CHARRÚA, Beatriz Jesucristo ungido y liberador: reflexión cristológica desde América Latina, Indo American Press Service, Bogotá, 1993, 378 pp.

CIDADE NOVA Jesus Cristo, Cidade Nova, São Paulo, 1983, 422 pp.

CIFUENTES, Ramón Angel La identidad de Jesús, Pehuén, Santiago, 1998, $116 \mathrm{pp}$.

CODINA, V. Seguir a Jesús hoy, Sígueme, Salamanca, 1988.

COLAVECCHIO, Ronaldo O caminho do Filho de Deus, Santuario, Aparecida, 1995, $220 \mathrm{pp}$.

COLlet, G., Der Christus der Armen. Das Christuszeugnis der lateinamerikanischen Theologen, Freiburg im Br., 1988.

COMBLIN, José A maior esperança, Petrópolis, Vozes, 1974, 116 pp.

COMBLIN, José El clamor de los oprimidos, el clamor de Jesús, Rehue, Santiago, 1986, $57 \mathrm{pp}$. 
COMBLIN, José Breve curso de teologia I: Jesus Cristo e a sua missão, Paulinas, São Paulo, 1983, 263 pp.

COMBLIN, J. Jesús de Nazaret, Sal Terrae, Santander, 1974, 104 pp.

COMBLIN, J. La oración de Jesús, Sal Terrae, Santander, 1977, 96 pp.

COMBLIN, J. El enviado del Padre, Sal Terrae, Santander, 1977, 104 pp.

COMBLIN, J. Cristo o la Iglesia de hoy y de mañana, Barcelona, 1966.

COMBLIN, J. Jesus e a preferência pelos pobres, Paulinas, Caxias do Sul, 1985.

COMBlin, J. A paixão e a morte de Jesus. O reino de Deus, Paulinas, São Paulo, 1990, 52 pp.

COMBLin, J. Jesus e a lei. A novidade de Jesus, Paulinas, Caxias do Sul, 1986.

COMBLIN, J. La resurrección de Jesucristo, Lohlé, Buenos Aires, 1962, 196 pp.

COMBLIN, Joseph Cristo en el Apocalipsis, Herder, Barcelona, 1969, 377 pp.

COMBLIN, J. El enviado del Padre: Jesús y el creyente en el evangelio de Juan, Sal Terrae, Santander, 1977, 102 pp.

COMISIÓN TEOLÓGICA DE LA COMPAÑíA DE JESÚS EN AMÉRICA LATINA, Jesucristo, prototipo de humanidad en América Latina, Obra Nacional de la Buena Prensa A.C., Ciudad de México, 2001, 171 pp.

CONFERENCIA EPISCOPAL DE CHILE Jesucristo ayer, hoy y mañana, Salesianos, Santiago, 1980, $63 \mathrm{pp}$.

CORREA PEDROSO, José Carlos El Cristo de Clara, Fundación Franciscana, Buenos Aires, 1998, 334 pp.

COSTADOAT, Jorge Cristo para el cuarto milenio. Siete cuentos contra veintiún artículos, Ediciones San Pablo, Santiago, 2001, 190 pp.

COY, Francisco El otro Jesús: El Espíritu Santo, la dinámica para hoy, Bautista, El Paso, 1974, 96 pp.

DAMIANO, Gilberto Aparecido Jesus e todas as crianças, Paulinas, São Paulo, 1988.

DANIELLS, Arthur Cristo nossa justiça: Uma visão pioneira da justificação pela fé, Tatui, 1988, $150 \mathrm{pp}$.

DE ANITUA, Santiago Estaré entre vosotros: reflexiones sobre el sermón eucarístico de Jesús, Libro Libre, San José, 1986, 370 pp.

DE CASTRO, Juan Anunciando a Jesucristo, Mundo, Santiago, 1972, 163 pp.

DE CASTRO, Claudio La ternura de Jesús, Paulinas, Santiago, 2002, 115 pp.

DE CONTO, Galdino Pedro Apocalipse do Terceiro Milênio, EST, Porto Alegre, 1999, $120 \mathrm{pp}$.

DE FERARI, José Manuel El hombre Jesús según los evangelios, Rehue, Santiago, 1989, 48 pp.

DEL RÍO, Eduardo Jesús, alias el Cristo, Grijalbo, México, 1985, 179 pp.

DÍAZ MATEOS, M. El Dios que libera, Lima, 1985.

DILAPSA Cristología y pastoral en América Latina, Dilapsa, Santiago, 1966, $223 \mathrm{pp}$.

DIEHL, Luis Ernesto y CATENA, Osvaldo Jesús, nuestro Salvador, Patria Grande, Buenos Aires, 1977.

DO AMARAL, Luciano Jesus te chama. A vocação cristâ no evangelho segundo Mateus, Loyola, São Paulo, 1990, 70 pp.

DOMÍNGUEZ, J. y SÁEZ, J. O homem de Nazaré, Petrópolis, Vozes, 1987, 216 pp. 
DONNAT, Francisco El mundo aymara y Jesucristo. El agente de pastoral en el camino del encuentro, de la inculturación y del diálogo interreligioso, Verbo Divino, Cochabamba, 1998, 136 pp.

DOYON, Jacques Cristologia para o nosso tempo, Paulinas, São Paulo, 1977.

DRI, Rubén La utopía de Jesús, Nuevomar, México, 1984, 301 pp.

DRI, Rubén Insurrección y resurrección. La práctica liberadora de Jesús de Nazaret, Centro de Estudios Ecuménicos, México, 1983, 177 pp.

ECHEGARAY, Hugo La práctica de Jesús, Lima, 1980.

EDITORIAL PAULINAS Dicionário teológico o Deus Cristão, Paulus, São Paulo, 1998, 976 pp.

EDWARDS, Aníbal Seguimiento de Cristo en América Latina. A propósito de “Beber en su propio pozo”, CEP, Lima, 1987, 104 pp.

ELIZONDO, Virgil (ed.) Vía crucis: La pasión de Cristo en América, Verbo Divino, Estella, 1993, 178 pp.

ELLACURÍA, I. Carácter político de la misión de Jesús, Lima 1974.

EPHRAIM Jesus, judeu praticante, Paulinas, Sâo Paulo, 1998, 417 pp.

EQUIPO SELADOC Cristología en América Latina, VI, Sígueme, Salamanca, 1984, 234 pp.

ESCOBAR ILLANES, P.V. Apuntes para una cristología en tiempos difíciles, Coll. Educación Humanista, México, Universidad Iberoamericana, 1977, $627 \mathrm{pp}$

ESPEZEL, Alberto Jesucristo. Vida y Pascua del Salvador, Buenos Aires, 1998, $192 \mathrm{pp}$.

ESQUERDA, Juan Signos del Buen Pastor, CELAM, Bogotá, 1991.

FABER LORENZEN, Lyme Introdução à Trinidade, Paulus, São Paulo, 2002, 159 pp.

FERNANDES, Jaime Jesus de Nazaré, Loyola, São Paulo, 1995.

FERNÁNDEZ-CARVAJAL, Francisco A Cruz de Cristo, Quadrante, São Paulo, 1999, $156 \mathrm{pp}$.

FERNANDES DE AQUINO, Marcelo, Jesus de Nazaré, profeta da libertade e da esperança, São Paulo, 1999, 398 pp.

FERRANDO, Miguel Ángel El Dios confiable. La revelación del Padre, del Hijo y del Espíritu Santo en la Biblia, Pontificia Universidad Católica, Santiago, 1993, 164 pp.

FERRANDO, Miguel Ángel Ver a Jesús, ver al Padre, PUC, Santiago, 2000, $275 \mathrm{pp}$.

FERRARO, Benedito Significação política e teológica da morte de Jesus à Luz do Novo Testamento, Vozes, Petrópolis, 1977.

FERRARO, B. Cristologia em tempos de ídolos e sacrificios, Paulinas, 1993, 112 pp.

FOIX, María Cecilia Jesús y los doce, Grupo Editorial Lumen, Humanitas, Buenos Aires-México, 2001, 139 pp.

FONTAINE, Pablo Jesucristo, una historia actual, Vicaría Pastoral Juvenil, 1989, 35 pp.

FORTE, Bruno Jesus de Nazaré, história de Deus, Deus da história: Ensaio de uma cristologia como história, Paulinas, São Paulo, 1990, 364 pp. 
FRANÇA MIRANDA, Mario de A pessoa e a mensagem de Jesus, Loyola, São Paulo, 2002, 257 pp.

FRANÇA MIRANDA, M. O Mistério de Deus em nossa vida. La doutrina trinitária de Karl Rahner, São Paulo, 1975.

FREYNE, Sean A Galiléia. Jesus e os evangelhos, Loyola, São Paulo, 1996, $254 \mathrm{pp}$.

GALDINO, Vitor $O$ Deus da revelação. A dialética entre revelação e libertação na teologia latino americana, Loyola, São Paulo, 1988, 344 pp.

GALILEA, S. La inserción en la vida de Jesús y en la misión, Paulinas, Bogotá, 1991.

GALILEA, Segundo Testigos de Cristo, Tiberíades, Santiago, 1998, 156 pp.

GALILEA, S. El seguimiento de Cristo, Paulinas, Bogotá, 1989.

GALILEA, Segundo Los días de Emaús, San Pablo, Santiago, 1983, 138 pp.

GALILEA, S.- VIDALES, R. Cristología y pastoral popular, Bogotá, 1974.

GALIZZI, Mario Eligió a los pobres. Evangelio según San Lucas, Don Bosco, Buenos Aires, 1980.

GALIZZI, Mario Jesús, víctima del poder. Comentario al evangelio según San Lucas, Don Bosco, Buenos Aires, 1981.

GALIZZI, Mario El largo camino de Jesús. Evangelio según San Lucas, II, Paulinas, Buenos Aires, 1981.

GALlEGO, Andrés Seguimiento de Jesús, en la cristología de Jon Sobrino, CEP, Lima, 1991.

GALVÃO, Antonio O Messias dos pobres, Ave Maria, São Paulo, 1996, 280 pp.

GARCÍA, Benjamín El Padre Nuestro hoy, Paulinas, Caracas, 1990, 83 pp.

GONZÁLEZ FAUS, J.I. y CASTILLO, A. Fe en Jesús y seguir a Jesús, CTR, México, 1978, 82 pp.

GONZÁLEZ, Antonio Trinidad y liberación. La Teología trinitaria considerada desde la perspectiva de la teología de la liberación, Uca, San Salvador, 1994, 247 pp.

GONZÁLEZ, C.I. Jesucristo ayer, hoy y siempre. Una proposición cristológica para la IV Conferencia de Santo Domingo (Auxiliar $N^{\circ} 3$ ), Ed. Celam, Santa Fe de Bogotá, 1992.

GONZÁLEZ, Carlos Ignacio Él es nuestra salvación. Cristología y soteriología, CELAM, Bogotá, 1991.

GONZÁLEZ, Carlos Ignacio El desarrollo dogmático de los concilios cristológicos, CELAM, Bogotá, 1991.

GONZÁLEZ, Carlos Ignacio Trinidad y Eucaristía, Cep, Lima, 1999, 181 pp.

GONZÁLEZ, Marcelo La Trinidad un nuevo nombre para Dios, Paulinas, Buenos Aires, 2000, 172 pp.

GONZÁLEZ, Marcelo et al. El misterio de la Trinidad en la preparación del gran Jubileo, San Pablo, Buenos Aires, 1997, 283 pp.

GOURGUES, Michel Fé, felicidade e sentido da vida, Paulinas, São Paulo, 1999, $105 \mathrm{pp}$.

GRACIO DAS NEVES, R. M. Dios resucita en la periferia. Hablar de Dios desde América Latina, Salamanca, 1991.

GRAU, José El reino de Dios, Certeza, Buenos Aires, 1974.

GRELOT, Pierre Dios, el Padre de Jesucristo, Paulinas, Buenos Aires, 1999, $320 \mathrm{pp}$. 
GREEN, Michael Jesucristo vive, Certeza, Buenos Aires, 1976.

GRENIER, Brian Jesus, o mestre, Paulus, São Paulo, 1997, 208 pp.

GRINGS, Dom Dadeus Creio na Santissima Trindade, Santuario Aparecida, 1999, 229 pp.

GUKIANI, Anselmo Cristo te ama, Loyola, Asunción, 1984, 68 pp.

GUTIÉRREZ, Gustavo El Dios de la vida, Lima, 1982.

GUTIÉRREZ, Gustavo En busca de los pobres de Jesucristo, Salamanca 1993.

HADDAD, Víctor Jesus em Mateus, Santuario, Aparecida, 1987, 128 pp.

HAMMES, Erico João Filii in Filo. A divinidade de Jesus como evangelho da filiação no seguimento. Um estudo em Jon Sobrino, Edipucrs, Porto Alegre, 1995, 142 pp.

HANSON, J. y HORSLEY, J. Bandidos, profetas e messias, Paulus, São Paulo, 1996, 620 pp.

HILGERT, Pedro Romão Jesus histórico, ponto de partida da cristologia latino-americana, Vozes, Petrópolis, 1987, 216 pp.

HOFMANS, Florencio Cristología, Instituto Catequístico Latinoamericano, Santiago, 1968, 184 pp.

HOORNAERT, Eduardo O movimento de Jesus, Vozes, Petrópolis, 1994, pp. 160; en castellano, Dabar, México, 1996, 192 pp.

HOORNAERT, Eduardo O Reino dos Céus, São Paulo, 1994, 118 pp.

INSTITUTO DE PASTORAL DE CAMPINAS Jesus está aquí, Vozes, Petrópolis, 1982, $216 \mathrm{pp}$.

INSTITUTO INTERNACIONAL DEL CORAZÓN DE JESÚS, Cristología en la perspectiva del corazón de Jesús, Bogotá, 1982.

IVANISE BOMBONATTO, Vera Seguimento de Jesus. Uma abordagem segundo a cristologia de Jon Sobrino, Paulinas, São Paulo, 2002, 494 pp.

JORDÁ, Miguel El divino Redentor (poemas-religiosidad popular), Santiago, 1984, 15 pp.

JORDÁ, Miguel Jesús Nazareno. Un aporte a la Nueva Evangelización, Paulinas, Santiago, 1989, 202 pp.

JORDÁ, Miguel El Mesías verdadero, San Pablo, Santiago de Chile, 1996.

JUAN PABLO II Cristología (catequesis), Fundación Cultural Nacional, Santiago, 1987, 385 pp.

KAPKIN, David La luz del Evangelio, Paulinas, Bogotá, 1983.

KAPKIN, David Historia de la pasión del Mesías, Universidad Pontificia Bolivariana, Medellín, 1987, 164 pp.

KELLENER, Wendelin $O$ filho do homem: a mensagem político-religiosa de Jesus, Paulinas, São Paulo, 1987, 186 pp.

KIRK, Andrés Jesucristo revolucionario, La Aurora, Buenos Aires, 1974.

KLAUSNER, J. Jesús de Nazaret, Paidós, Buenos Aires, 1971.

KLOPPENBURG, Boaventura Abba: Papai (Deus Pai Eterno), Vozes, Petrópolis, 1999, $171 \mathrm{pp}$.

KLOPPENBURG, Boaventura Trindade (o amor em Deus), Vozes, Petrópolis, 1999, $180 \mathrm{pp}$.

KUNZ, Marilyn El rey siervo, Certeza, Buenos Aires, 1975.

LA CASA DE LA BIBLIA O verdadero rosto de Jesus. Guia para uma leitura comunitária do evangelho de Marcos, Paulinas, São Paulo, 2002, 197 pp. 
LADD, George Eldon Vendré otra vez, Certeza, Buenos Aires, 1973.

LAGNI, Daniel Jesus um homem de fe?, Redentorista, Goiania, 1999.

LECLERC, Eloy O Reino escondido, Petrópolis, Vozes, 1989, 166 pp.

LEITE, Oliveira Cristo e a contestação política. Relacionamento de Cristo com o partido zelota, Vozes, Petrópolis, 1974.

LIBANIO, João Batista y BOFF, Leonardo Seguimiento de Jesús junto al enfermo, Indo American Press Service, Bogotá, 1980.

LÓPEZ TRUJILLO, Alfonso La cristología: perspectivas actuales en América latina, Consejo Episcopal Latinoamericano, s/f, 38 pp.

LUM, Ada Jesús, el forjador de discípulos, Certeza, Buenos Aires, 1975.

LUM, Ada Jesús el radical, Certeza, Buenos Aires, 1976.

MAGAÑA, José Jesus libertador dos oprimidos, Edições Loyola, São Paulo, 1990, 342 pp.

MAGAÑA, José Jesús liberador: hacia una espiritualidad desde los empobrecidos, México, Librería parroquial, 1985, 394 pp.

MAGNANI, Giovanni Jesus, construtor e mestre, Santuario, Aparecida, 1998, $280 \mathrm{pp}$.

MALDONADO, Luis La "exaltación” de Jesús en la cruz según el cuarto evangelio, EDUC, Quito, 1980.

MARTÍN RODRÍGUEZ, Francisco Jesús, relato histórico de Deus. Cristologia para vivir e rezar, Paulinas, São Paulo, 1997, 270 pp.

MATEO, Juan y CAMACHO, Fernando Jesús e a sociedade de seu tempo, 1993, 176 pp.

MAUSON, T.W. O ensino de Jesus, Aste, São Paulo, 1965, 378 pp.

MAZARIEGOS, Emilio Seducidos por el crucificado, San Pablo, Santa Fe de Bogotá, 2001, 220 pp.

MEDINA, Jorge Señor ¿quién eres tú?, Universidad Católica de Chile, Santiago, 1983, $145 \mathrm{pp}$.

MÉNDEZ-PEÑATE, Adriana Jesús. Manual para leer el evangelio de Marcos, CTR, México, 1990, 81 pp.

MESQUITA GALVÃO, Antonio O Messias dos pobres, Ave Maria, São Paulo, 1996, $426 \mathrm{pp}$.

MESSORI, V. Padeceu sob Póncio Pilatos. Uma pesquisa sobre a paixão e morte de Jesús, Aparecida, Santuário, 1993, 374 pp.

MESTERS, Carlos La práctica liberadora de Jesús, Rehue, Santiago, 1987, 27 pp.

MESTERS, Carlos Deus, onde estás?, Vega, Belo Horizonte, 1976.

MESTERS, Carlos Jesús nuestro hermano, Dabar, México, 1996, 226 pp.

MESTERS, C. Jesús de los evangelios para seguirlo hoy, Ediciones Mundo, Santiago, 1997.

MESTERS, C. Con Jesús, ¿sí o no?, Verbo Divino, Navarra, 1998 (portugués: 1995), $150 \mathrm{pp}$.

MESTERS, C. En camino con Jesús: lectura del evangelio de Marcos, Estella, Verbo Divino, 1998, 89 pp.

MIGUES BONINO, José (ed) Faces of Jesus: latin american christologies, Orbis Books, New York, 1985, 186 pp.

MIRANDA, J.P. El ser y el mesías, Salamanca, 1973. 
MORACHO, Félix Jesús de Nazaret: el hombre libre y liberador, Educación y Cultura Religiosa, Caracas, 1988, 48 pp.

MORACHO, Félix Seguir a Jesús. Catequesis para comunidades cristianas, Paulinas, Bogotá, 1988, 131 pp.

MORACHO, Félix Como leer os evangelhos. Para entender o que Jesus fazia e dizia, San Pablo, 1993, 208 pp.

MORACHO, Félix A familia e Jesus de Nazaré, San Pablo, 1993, 104 pp.

MORACHO, Félix Lo que Jesús hacía y decía, San Pablo, Bogotá, 1996, $200 \mathrm{pp}$.

MORIN, Emile Jesus e as estruturas de seu tempo, Paulinas, São Paulo, 1981.

MORONTA, Mario El Cristo de nuestra fe (Reflexiones a partir de la cristología de la religiosidad popular venezolana), Caracas, Gráficas Monfort, 1991.

MOSCONI, Luis La Buena Noticia de Jesús según San Mateo, Dabar, México, 1993, $80 \mathrm{pp}$.

MOSCONI, Luis Evangelho de Jesus Cristo segundo Marcos, Loyola, São Paulo, 1997, 127 pp.; en castellano, Dabar, México, 1993, 79 pp.

MOSER, Antonio Morte e Ressurreição de Jesus Cristo, 1993, 16 pp.

MULLER, Charles Dios con nosotros: Jesucristo, ONAC, Santiago, 1982, 250 pp.

MUÑOZ, Ronaldo El Dios de los Cristianos, Paulinas, Buenos Aires, 1987, 274 pp.

MUÑOZ, Ronaldo La Trinidad de Dios amor ofrecido en Cristo Jesús, San Pablo, Santiago, 2000, 50 pp.

MYRE, André Abbá: la oración de los discípulos de Jesús, La Biblia en Oración, Bogotá, 1989, 40 pp.

NARDONI, Enrique La transfiguración de Jesús y el diálogo sobre Elías, según el evangelio de San Marcos, Patria Grande, Buenos Aires, 1977.

NEUTZLING, Inácio O reino de Deus e os pobres, Loyola, São Paulo, 1986, $255 \mathrm{pp}$.

NOLAN, A. Jesús antes do cristianismo, Paulinas, São Paulo, 1989, 208 pp.

OLIVEROS, Roberto Seguimiento de Cristo en las comunidades eclesiales de base, Clar 66, Bogotá, 1994, 172 pp.

OLVERA DELGADILLO, J. De Dios Metodología cristológica y reflexión pastoral en América Latina, Celam, Bogotá, 1993, 457 pp.

OTERO, Miguel La piedra que era Cristo, Plaza-Sacres, Madrid, 1984.

PAGOLA, José Antonio Jesucristo. Catequesis cristológicas, CTR, México, 1990, 65 pp.

PALACIO, Carlos Jesucristo. Historia e interpretación, Madrid, 1978, 257 pp.

PARKS, Tomás, Intriga en la corte: Anás y la conspiración contra Jesús, Bautista, El Paso, 1973, 112 pp.

PEÑA ÁlVAREZ, Sergio El Niño Dios de Sotaquí, Ed. Caburga, La Serena, 1996, 98 pp.

PERDIA, Mateo et al. El seguimiento de Cristo crucificado, Paulinas, México, 1985, 200 pp.

PEREGRINO SALCEDO, Roberto Jesús, el dolor que cura de palabra, San Pablo, Buenos Aires, 1994, 136 pp.

PEREGRINO, Roberto Jesús chamuyaba en parábolas, el evangelio en lunfardo, San Pablo, Buenos Aires, 1994, 132 pp. 
PERSCH, Leo Parusia ou a próxima volta de Cristo, 1994, 184 pp.

PESSATI, Jordão Amigo e salvador, Paulinas, São Paulo, 1974, 94 pp.

PÍFFARI, P. Itinerarios de la experiencia trinitaria de salvación en Cristo. Hacia el tercer milenio, Editorial Don Bosco, Asunción, 1996.

PIHNO, Arnaldo Cardoso de Uma cristologia para a identidade cristâ na modernidade: o pensamento cristológico de D. António Ferreira Gomes, Universidad Pontificia de Salamanca, Salamanca, 1998, 328 pp.

PIKAZA, Xavier A figura de Jesus. Profeta, taumaturgo, rabiano, messias, Vozes, Petrópolis, 1995, 204 pp.

PIXLEY, Jorge Reino de Dios, La Aurora, Buenos Aires, 1977.

PIXLEY, Jorge La resurrección de Jesús, el Cristo, Cieets, Managua, 1997, 169 pp.

PIXLEY, Jorge Vida no Espirito, Vozes, Petrópolis, 1997, 282 pp.

POMPEU DE CAMPOS, Euler Jesús: el hombre de aquel viernes, Paulinas, Santiago, 1980, 62 pp.

PONGUTA, Silvestre Él es la imagen de Dios invisible, Abs., Caracas, 1991, $129 \mathrm{pp}$.

PONGUTA, Silvestre El evangelio de Dios, Asociación Bíblica Salesiana, Caracas, 1992, $265 \mathrm{pp}$.

POULAR, Emile Jesus, a Galáxia, Paulinas, São Paulo, 1999, 179 pp.

POZO, Cándido La venida del Señor en la Gloria Escatológica, Edicep, México, 1993, $228 \mathrm{pp}$.

PULGA, R. y SARAVIA, X. O Caminho de Jesus: Terra o povo; prática, caminho, Paulinas, São Paulo, 1988, 64 pp.

RAMÍREZ, Dagoberto Jesús I y Jesús II, Comunidad Teológica Evangélica, Santiago, 1986, $52 \mathrm{pp}$.

RAMÍREZ, Dagoberto Antología. Jesús de Nazaret, Comunidad Teológica Evangélica, Santiago, 1987, 194 pp.

RENDERS, Pablo Figuras de la pasión, Paulinas, Santiago, 1992, 51 pp.

RIBEIRO, Helcion A encarnação de nosso Deus e a realização do homem, Loyola, São Paulo, 1993, 67 pp.

RIBEIRO, Ivete O nazareno. Fatos e palavras, Petrópolis, Vozes, 1975, 82 pp.

RIDDERBOS, Hernán La venida del Reino, La Aurora, Buenos Aires, 1985.

RIVAS, Luis La oración que Jesús nos enseñó, Patria Grande, Buenos Aires, 1977.

ROMELLINI, F. y MORETTI, G. Tinha rosto e palavras de homen. Um perfil de Jesus, Paulinas, São Paulo, 1999, 116 pp.

ROCHA, Mateus Quém é este homem?, Duas Cidades, São Paulo, 1969, 134 pp.

RODERO FLORIÁN, Antonio En la escuela de Cristo. Jubileo 2000, Edicep, México, 1996, 152 pp.

RODRÍGUEZ, Eudoro Cristo: una aproximación latinoamericana, USTA, Bogotá, $1985,84 \mathrm{pp}$.

ROOS, Jorge Vivió en Nazaret, Paulinas, Buenos Aires, 1984.

ROSAS, Guillermo El misterio de Cristo en el año de la Iglesia: el año litúrgico en Odo Casel, en Anales de la Facultad de Teología, Santiago, N 2, 1996, 194 pp.

RUIZ ARENAS, O. Jesús, epifanía del amor del Padre. Teología de la revelación, Celam, Bogotá, 1989. 
S/A Cristología y pastoral popular, Paulinas, Bogotá, 1974.

SALGADO, Plínio Vida de Jesus, Editora da Universidade Federal de Mato Grosso, Cuiabá, 1997, 666 pp.

SÁNCHEZ ROJAS, Gustavo Jesucristo reconciliador (tesis doctoral centrada en la enseñanza de San Agustín), Universidad de Lima, Lima, 1996, 198 pp.

SANDER, Luís Marcos Jesus o libertador. A cristologia da libertação de Leonardo Boff, Sinodal, São Paulo, 1986, 288 pp.

SANTOS, Mons. José Manuel Las grandes opciones de Cristo, Paulinas, Santiago, 1987, $70 \mathrm{pp}$.

SCARDELAI, Donizete Movimentos messiánicos no tempo de Jesus, Paulus, São Paulo, 1998, 377 pp.

SCHILSON, A. y KASPER, W. Cristologia: Abordagens contemporâneas, Loyola, São Paulo, 1990, 160 pp.

SEGUNDO, Juan Luis Nuestra idea de Dios, Carlos Lohlé, Buenos Aires, 1969.

SEGUNDO, Juan Luis El hombre de hoy ante Jesús de Nazaret, 2 vol., Cristiandad, Madrid, 1982.

SEGUNDO, Juan Luis La historia perdida y recuperada de Jesús de Nazaret, Sal Terrae, Santander, 1991.

SILVA HENRÍQUEZ, CARD. Jesús, hijo de carpintero (Homilía), Vicaría de la Solidaridad, Santiago, 1976, 32 pp.

SILVA, S. ¿Por qué murió Jesús?: Iniciación a los evangelios, Volumen I: Lectura del drama; Volumen II: Lectura del escenario: naturaleza, persona y cultura, Ed. Universidad Católica de Chile, Santiago, 1996 y 1999.

SIMPSON, A. B. Jesus Cristo, ele mesmo. A relação que faz a diferença, Venda Nova, Betânia, 1990, 152 pp.

SOBRAL, José Atividade pública de Jesus, Paulinas, São Paulo, 1989.

SOBRINO, J. Cristología desde América Latina. Esbozo a partir del seguimiento del Jesús histórico, Ediciones CRT, México, 1976, 330 pp.

SOBRINO, J. Jesucristo Liberador, Ed. Trotta, Madrid, 1991, 350 pp.

SOBRINO. J. La fe en Jesucristo. Ensayo desde las víctimas, Ed. Trotta, Madrid, 1999, $508 \mathrm{pp}$.

SOBRINO, J. Jesús en América Latina. Su significado para la fe y la cristología, Santander, 1982, 261 pp.

SOBRINO, J. La oración de Jesús y del cristiano, Paulinas, Bogotá, 1981, 95 pp.

SOBRINO, J. El Cristo de los Ejercicios Espirituales, Sal Terrae, Aquí y ahora 9, Bilbao, 1990, $32 \mathrm{pp}$.

SOCIEDAD ARGENTINA DE TEOLOGÍA (Editor) El misterio de Cristo como paradigma teológico, XIX Semana Argentina de Teología en los 30 años de la SAT, San Benito, Buenos Aires, 2001, 218 pp.

SOCIEDADES BÍBLICAS UNIDAS, Jesús, modelo de hombre nuevo, Mexicana, México, 1975, 128 pp.

SOCIEDAD CHILENA DE TEOLOGÍA (ed.) Cómo hablar del Dios de Jesucristo hoy, San Pablo, Santiago, 1994, 163 pp.

SOUBLETTE, Gastón Rostro de hombre, Andrés Bello, Santiago, 1997, 557 pp.

SPERANDO, Wilson João Meu encontro com Cristo, Petrópolis, Vozes, 1988, 100 pp. 
STORNIOLO, Ivo As tentações de Jesus, Paulinas, Caxias do Sul, 1988, 53 pp.

STOTT, John Las controversias de Jesús, Certeza, Buenos Aires, 1975.

STOTT, John Cristianismo básico, un libro para aquellos que quieren conocer la verdad acerca de Jesucristo, Buenos Aires, Certeza, 1977, 214 pp.

SUSIN, Luiz Carlos Jesus Filho de Deus e Filho de Maria. Ensaio de cristologia narrativa, Paulinas, São Paulo, 1997, 200 pp.

SWIDLER, Leonard Ieshua. Jesús histórico, cristologia, ecumenismo, Paulinas, São Paulo, 1993, 163 pp.

TARDIF, Emiliano Jesús es el mesías, San Pablo, Santiago, 1990, 161 pp.

TARDIF, Emiliano Jesús está vivo, Publicaciones Kerygma, México, 1984, $141 \mathrm{pp}$.

TAUFER, G.P. Poseídos por Jesús, Paulinas, Bogotá, 1993, 107 pp.

TAVARES, Sinivaldo S. Il mistero della croce nei teologi della liberazione latino-americani, Pontificium athennaeum antonianum, Roma, 1999, 325 pp.

TERRA, João Ev. Jesus político e libertação escatológica, Loyola, São Paulo, 1979.

TERRA, João Ev. Escatologia e resurreição, Loyola, São Paulo, 1979.

TERRA, João Ev. Jesus histórico e o Cristo querigmático, Loyola, São Paulo, 1977.

TERRA, João Ev. Jesus de Nazaré nos Evangelhos Sinóticos, Loyola, São Paulo, 1991, 78 pp.

THIVOLLIER, P. Ele viveu entre nós, Paulinas, São Paulo, 1990, 354 pp.

TREVISAN, Lauro A fé que remove montanhas, Vozes, Petrópolis, 1995, 158 pp.

TREVISAN, Lauro Jesús precursor e anunciador da nova era, Santa Maria, Da Mente, 1993, 223 pp.

TRIGO, Pedro Los Cristos de América Latina. Curso latinoamericano de cristianismo, Ed. Centro Gumilla, $\mathrm{N}^{\circ} 10$, Venezuela (s/d), $32 \mathrm{pp}$.

VALLA, Héctor Conducta de Cristo, conducta de cristiano, Claretiana, Buenos Aires, 1984.

VALLEJO, Luis Jesús, el maestro. Pastoral catequética, Universidad Santo Tomás, Bogotá, 1986, 449 pp.

VAN NIEUWENHOVE, Jacques (ed.) Jésus et la libération en Amérique Latine, Desclée, Paris, 1986.

VARGAS-MACHUCA, Antonio (Ed.) Jesucristo en la historia y en la fe, Salamanca, 1977.

VAZ, Armindo Jesus, o orante e mestre da oração, Carmelo, Oeiras, 1987, $114 \mathrm{pp}$.

VERMES, G. Jesus o judeu. Uma leitura dos evangelhos, feita por um historiador, Loyola, São Paulo, 1990, 232 pp.

VICARÍA DE LA SOLIDARIDAD Jesús de Nazaret, Vicaría de la Solidaridad, Santiago, 1976, 112 pp.

VIGIL, José Ignacio y LÓPEZ, María Un tal Jesús, UCA, Tomos I y Iglesia, 1982.

VILDA, Carmelo Se llamaba Jesús de Nazaret, Educación y Cultura Religiosa, Caracas, 1989,88 pp.

VILLAMÁN, Marcos Mesianismo y poder en el evangelio de Marcos, Centro Antonio Montesinos, México, 1988, 189 pp.

VILLAMÁN, Marcos Leyendo el evangelio de Lucas, Centro Antonio Montesinos, México, 1990, 133 pp. 
VIRGILIO, P. Cristo é a resposta, Paulus, São Paulo, 1996, 224 pp.

VOLKMANN, Martín Jesús e o templo, Paulinas, 1993, 170 pp.

WALKER, Alan Jesús y los conflictos humanos, La Aurora, Buenos Aires, 1969.

WEBWE, Hans Jesús y los niños, CELADEC, Lima, 1980, 135 pp.

WETPHAL, Euler Renato O Deus cristão: um estudo sobre a teologia trinitaria em Leonardo Boff, Escola Superior de Teologia, São Leopoldo, 1997.

ZAÑARTU, Sergio Historia del Dogma de la Encarnación, desde el siglo V al VII, Universidad Católica de Chile, Santiago, 1995, 148 pp.

ZEA, V. Jesús, el Hijo de Dios, USTA, Bogotá, 1981, 224 pp.

ZEZINHO, Padre Cristo me dejó preocupado, Paulinas, Santiago, 1989, 150 pp.

ZILLES, Urbano Jesus Cristo. Quem é este?, Edipucrgs, Porto Alegre, 1999, 304 pp.

\section{ARTÍCULOS}

ADINALFI, Marco “Jesús realiza la primera emancipación de la mujer", Vida Pastoral, 17/53 (1989) 18-23.

AETABLE, Luis "La utopía de Jesús sigue siendo válida", Pastoral Misionera, (1983) 419.

AGUILERA, M. Guadalupe "Los sacramentos, lugar de encuentro con Cristo Salvador", Senderos, 30 (1987) 48-57.

AHUMADA, José "Jesucristo, compasión por el ser humano doliente", Testimonio, 135 (1993) 21-27.

AHUMADA, Vicente "Cristo, ayer y hoy”, Revista Católica, 1057 (1983) 50.

ALEGRE, Javier "La Iglesia que Jesús quería”, Diakonia, 13/51 (1989) 233-268.

ALEMANY, José "Jesús Cristo, realizacão da caridade", Grande Sinal, 34/1 (1980) 19-26.

ALESSANDRI, Hernán "Cristo redime a la Familia", Servicio, 77 (1983) 227.

ALESSANDRI, Hernán "La dimensión mariana de Cristo", Carisma, 29 (1991) 35-80.

ALFARO, Juan “Análisis del libro Jesús en América Latina de Jon Sobrino", Encuentros, 34 (1983) 146-154.

ALLIENDE, Joaquín "La peregrinación, memoria del Verbo", Revista Católica, 1058 (1983) 30.

ALLIENDE, Jimena “Cristo peregrino y misionero", Mensaje, 30/296 (1981) 22-24.

ALONSO, Jorge, sj, "La liberación del hombre es la gloria de Dios. I. Fundamentación teológica; II. Una teología de la cruz", Christus, 38/446 (1973) 15-26.

ALONSO, Jorge, sj, "El poder del pueblo no es Cristo", Christus, 40/480 (1975) 29-30.

ALONSO, Severino "La vida religiosa como seguimiento de Jesús", Testimonio, 111 (1989) 5-13.

ALTAMIRA, Alfredo "El evangelio de Jesucristo, fuerza de liberación I", Cias, 38 (1989) 364-384; Cias, 386 (1989) 413-433.

ALVARADO, Napoleón "Y Dios se hizo Job en Jesús", Diakonia, 45 (1988) 47-68; Christus, 53/620 (1989), 60-66. 
ÁLVAREZ, Jorge "Nazaret: su significado para Jesús y para la Iglesia”, Páginas,15/105 (1990) 15-31.

ÁLVAREZ, Ariel “PPor qué Judas traicionó a Jesús?”, Didascalia, 459 (1993) 37-42.

ALVES DES SANTOS, Fabio "De Moisés ao evento Jesús”, Teo-comunicaçâo, 20/88 (1990) 117-124.

ALVEAR, Enrique "Desde Cristo Solidario construimos una Iglesia Solidaria", Servicio 43 (1985) 92.

AMAYA TORRES, Fabián "Reflexiones teológicas sobre la cruz", Nuevo Mundo, 35 (1988) 5-12; Christus, 583-584 (1985) 15-18.

ANASAGASTI, Pedro de, "Comprometernos con Cristo a construir una nueva América Latina”, Ecclesia 2565 (1992) 14-15.

ANDRADE PONTE, Eduardo "A morte de Cristo e a Libertação Temporal dos Homens", Reb, 28/2 (1968) 328.

ANGE DE MEAUDOU, Daniel "La contemplación del costado abierto. Por una inspiración", Tierra Nueva, 32 (1980) 64-82.

ANTELO, P. Adolfo "Abrid las Puertas a Cristo", Nexo, 1 (1983) 11-12.

ANTONICH, Ricardo "Conocer a Jesucristo para amarle y seguirle", Cuadernos de espiritualidad, 26 (1983) 5.

ANTONICH, Ricardo "Mirar al mundo desde el corazón de Cristo", Cuadernos de espiritualidad, 28 (1983) 28.

ANTIONAZZI, Alberto "Jesús Cristo e o mesmo onten, hoje e sempre consequencias para a eclosiología”, Actualização, 21 /236 (1992) 153-160.

ARCE, Sergio "Jesús alimenta a las multitudes: una crítica a la economía al mercado”, Cristianismo y Sociedad, 114 (1992) 7-24.

ARIAS, Mortimer "Misión y liberación. La proclamación del jubileo en el mensaje de Jesús y en la misión cristiana hoy", Vida y pensamiento, 3/1 y 2, (1983) 31.

ARIAS REYERO, Maximino "Confesar a Jesús en América Latina. La perspectiva de Puebla", Communio, 2/5 (1983) 35.

ARIAS REYERO, Maximino "La cristología del Documento de Puebla", Teología y Vida, 21/2 (1980) 129-148.

ARIAS REYERO, Maximino "Cristología popular en el Documento de Puebla”, Revista Católica, 1054 (1982) 14; Tierra Nueva, 10/38 (1981) 32-40.

ARIAS REYERO, Maximino "Hablar de Jesucristo hoy", Revista Católica, 1060 (1983) 39.

ARIAS REYERO, Maximino “Jesucristo y la Iglesia”, Revista Católica, 1075 (1987) 199-204.

ARIAS REYERO, Maximino "Jesús hombre creyente en el Nuevo Testamento", Digesto Familiar, 29/189 (1991) 6-8.

ARNAIZ, José M. "Evangelizar es anunciar lo que Jesús hizo y hacer lo que Él anunció", Testimonio, 117 (1990) 8-14.

ARNAIZ, José M. “Jesús, el apasionado del Reino", Testimonio, 135 (1993) 5-13.

ARNS, Paulo Evaristo "Amar a Cristo e servir ao Povo de Deus", Grande Sinal, 43 (1989) 655-660.

ARNS, Paulo Evaristo, "En las Conquistas de la Revolución descubrimos las señales del Reino de Dios", Solidaridad, 12/101 (1989) 21.

ARRAZA, Carlos “¡Jesús vive!”, Nuevo Mundo, 85 (1979) 17-21. 
ARRUPE, P., s.j., "Oração a Cristo nosso modelo", Grande Senal, 9/10 (1982) 747.

ARRUPE, P., s.j., "Qué significa el corazón de Cristo", Boletín de espiritualidad, 91 (1985) 20.

ARRUPE, P., s.j., “El corazón de Cristo”, Boletín de espiritualidad, 77 (1982) 2.

ARRUPE, P., s.j., "El corazón de Cristo centro del misterio cristiano", Cuadernos de espiritualidad, 28 (1983) 13.

ARRUPE, P., s.j., "Fe Cristo e ação missioneria", Revista de cultura bíblica, 26/7 (1983) 35-58

ASIAIN, Justo, "La sensibilidad de Jesús", Didascalia, 42/1 (1988) 4-13.

ASSMANN, H. "La actuación histórica del poder de Cristo", en R. Gibellini (Ed.) La nueva frontera de la teología en América Latina, Salamanca, 1977, pp. 133-144.

AUER, Johann SAC, "Devoción al corazón de Jesús y la Teología de la conversión”, Tierra Nueva, 46 (1983) 62

AYESTERÁN, J.C. "La cristología de Puebla", en Equipo SELADOC, Puebla, V, Sígueme, Salamanca, 1981, pp. 175-198.

AZUELA, Fernando, s.j., “CCómo predicar la muerte de Jesús en un continente crucificado", Christus, 42 (1977) 30 - 33; Solidaridad, 6 (1984) 35.

AZZI, Riolando, "Do Bom Jesus sofredor ao Cristo Libertador", Perspectiva Teologica, 18 (1986) 215-233.

BACARREZA R, Felipe Mons. "Del corazón abierto de Cristo nace la Iglesia I", Revista Católica, 90 (1990) 115-125.

BACARREZA, Felipe Mons. "Del corazón abierto de Cristo nace la Iglesia II", Tierra Nueva, 21 (1992) 53-78; Revista Católica, 90 (1990) 291-303.

BAENA, Gustavo "El sacerdocio de Cristo", Diakonía, 26 (1983) 122.

BAGGIO FREI, Hugo “O profeta Jesus de Nazaré”, Convergencia 21 (1986) 146- 58.

BANDERA, Armando S.P. "La muerte de Jesucristo en la cristología de Leonardo Boff”, Tierra Nueva, 39 (1981) 19.

BARRIOLA, Miguel Antonio "El corazón de Cristo, camino viviente de la Nueva Alianza", Tierra Nueva, 32 (1980) 42-63.

BARRIOLA, Miguel Antonio "El corazón de Cristo en la perspectiva de la experiencia mística", Tierra Nueva, 44 (1983) 76.

BARRIOLA, Miguel Antonio "Getsemaní: protesta filial de Cristo", Libro Anual (1975) 67-102.

BARRIOLA, Miguel Antonio "Jesús, los pobres y los otros”, Tierra Nueva, 17 (1989) 24-29; Tierra Nueva, 18 (1989) 47-61; Tierra Nueva 19 (1990) 54-82.

BARTOLOMÉ, Juan I. "Jesús ante el dinero, nadie puede servir a dos señores", Sal Terrae, 6 (1990) 449-459.

BEAUDIN, M. "Une christologie d'Amérique Latine" (J. Sobrino), Science et Esprit 41 (1989) 361-369.

BENTUÉ, Antonio "Fe en Jesucristo y racionalidad", Teología y Vida, 3 (1983) 143.

BERGOGLIO, J.M. "Cruz y sentido Bélico de la Vida”, Boletín de Espiritualidad, 85 (1984), 1.

BERTOLI, Paolo, Card. "Jesús, evangelio de Dios y evangelizador", Documentación Celam, 14 (1978) 1-9. 
BLEST, Clotario "La liberación en Cristo", Presencia, 11 (1986), 18-20.

BOESAR, Allan "Jesucristo, vida del mundo", Actualidad Pastoral, XVI/150 (1983) 306.

BOFF, Leonardo "La liberación de Jesucristo a través del camino del opresor", En R. Gibellini (Ed.) La nueva frontera de la teología en América Latina, Salamanca, 1977.

BOFF, Leonardo "Cómo predicar la Cruz hoy en una sociedad de Crucificados", Nuevo Mundo, 36 (1988) 81-96.

BOFF, Leonardo "Para predicar y vivir la cruz de Jesús", Senderos, 31 (1988) 12-25.

BOFF, Leonardo - KLOPPENBURG Boaventura, ofm "La conciencia de Jesús", Medellín, 41 (1985), 17-28.

BOFF, Leonardo “¿Dónde encontramos hoy a Cristo resucitado”, Cuadernos de Espiritualidad, 22 (1982) 30.

BONET, Luis "Para una liturgia más conforme al Cristo humilde y pobre", Phase, 31 (1991) 241-248.

BONINO, José Miguez "Jesucristo: vocación comprometida con el Reino", Actualidad Pastoral, 144 (1982) 285.

BORRAT, H. "El Cristo de la fe y los Cristos de América Latina. Para una cristología de la vanguardia", Víspera, 37 (1970) 26-31.

BOYLAN, Eugenio “La Madre del Cristo total”, Trípode, 169 (1980) 15-17.

BRAKENMEIER, Gattfried "Os culpados da morte de Jesús", Estudios Teológicos, 30 (1990) 206-223.

BRANDLE, Francisco "El Jesús que transformó a Pablo", Revista de Espiritualidad, 47 (1988) 49-64.

BRANDLE, Francisco "El misterio de navidad o el nacimiento de Dios en el mundo y en el hombre", Revista de Espiritualidad, 45 (1986) 37-52.

BRAVO, Carlos “Abba, Padre”, Christus 45 (1980) 17

BRAVO, Carlos "Palabras de Dios sobre el exilio y el destierro", Christus, 588 (1985) 45-51.

BRAVO, Carlos “Comida de Jesús y cena del Señor”, Christus, 54 (1989) 17-23.

BRAVO, Carlos “¿Qué significa el título Hijo de Dios, aplicado a Jesús”, Theologica Xaveriana, 41 (1991) 7-42.

BRAVO, Carlos "La búsqueda de sentido de la muerte de Jesús", Christus, 49 (1984) 21.

BRAVO, Carlos "Hacia una espiritualidad del seguimiento a la luz del carisma del corazón de Jesús", Christus, 41 (1991) 35-37

BRAVO, Carlos "Cristo, sacramento de misericordia del Padre", Christus, 41 (1991) 29-34.

BRAVO, Carlos "El pobre, clave del juicio de los hombres" Christus, 45 (1980) 31-37.

BRAVO, Carlos “Jesús y la liberación de la maldición”, Christus, 53 (1988) 35-37.

BRAVO, Carlos "Una cristología abierta al Jesús histórico y su seguimiento", Efemérides mexicana, 9 (1991) 155-170.

BRAVO, Ernesto "Jesucristo el esposo", Vida Pastoral, 18 (1990) 46-47.

BRAVO, Ernesto “Jesucristo el Primogénito”, Vida Pastoral, 18 (1990) 41-42. 
BRIANCESCO, Eduardo "Sentido y vigencia de la cristología de San Anselmo. Ensayo de lectura estructural del "cur deus homo" (I ${ }^{\mathrm{a}}$ parte)", Stromata, 37 (1981) 3-18.

BRIANCESCO, Eduardo "Sentido y vigencia de la cristología de Anselmo (2 parte)", Stromata, 38 (1982) 283

BRUNELLI, Delier "O natal de Jesús: um sinal profetico", Convergencia, 21 (1986) 603-610.

BUELA, M, Carlos Miguel "La divinidad de Cristo", Mikaél, 7 (1979) 57-80

BULNES, Sanfuente, Francisco "Mi experiencia de Cristo", Mensaje, 293 (1980) 545-548.

CABELLO, Rubén, s.j. "La misión de Jesús y el año acepto al Señor: Lc. 4,1819 - Comentario exegético", Christus, 472 (1975) 28-33.

CABELLO, Rubén, s.j "El Reino de Dios”, Christus 585 (1985) 16-22.

CABELLO, Rubén, s.j "Reino de Dios y seguimiento de Jesús", Christus, 581 (1984) 36.

CABELLO, Rubén, s.j. "La Resurrección de Cristo y nosotros", Christus, 455 (1973) 20-26.

CABELlO, Rubén, s.j. "El sacerdocio de Cristo en la carta de los Hebreos Apuntes para una reflexión”, Christus, 460 (1974) 16-21.

CADAVID Duque, Luis Álvaro "Evangelización de la cultura, opción por los pobres y Cristología, la propuesta de la teología de la Liberación”, Medellín 62 (1990) 188 - 219.

CAJIAO, Silvio “Biblia y Cristología”, Theologica Xaveriana 88 (1988) 283-289.

CALDERÓN, Carlos Alberto "Seguir a Jesús hoy al estilo de las bienaventuranzas", Medellín 66 (1991) 257-268.

CALIMAN, Cleto, sdb "O seguimiento de Cristo Hoje na America Latina", Convergencia, 125 (1979) 394-404.

CAMBÓN, Enrique "Abandono de Cristo en la cruz, teología actual y futuro de la Iglesia", Medellín, 23 (1980) 332-351.

CAMPOS, Miguel Ángel “¿Por qué murió Jesús?”, Christus 496 (1977) 17 - 21.

CAPMANY, José, Mons “Apuntes sobre la Cristología en el desarrollo de la sociología en la Iglesia desde León XIII hasta Juan Pablo II”, Tierra Nueva, 39 (1981) 78.

CAPMANY, José, Mons "La persona y el amor de Jesús en la ordenación social", Tierra Nueva, 39 (1981) 52.

CARDENAL, José María “A devoção ao coração de Jesús para o Homen de hoje", Grande Sinal, 44 (1990) 403-413.

CÁRDENAS Pallares, José “Jesús, hijo de María el Pobre”, Servir - Teología y Pastoral, 95-96 (1981) 395.

CÁRDENAS Pallares, José "El misterio del Reinado de Dios", Servir, 106 (1984) 215.

CÁRDENAS Pallares, José “El poder liberador de Jesús”, Servir, 98 (1982) 163.

CARIBAY, Xavier "La práctica de Jesús: Resumen del Libro de Hugo Etchegaray", Christus 552 (1982) 33.

CARRERAS, José María "La Cristología de San Ignacio", Revista Teológica Limense 1 (1990) 47-69. 
CARRILlO Alday, Salvador "La Alianza en Cristo Jesús", Medellín 46 (1986) 216-253.

CARRILLO Alday, Salvador "La persona de Jesús" (II), Pentecostés 3 (1991) 8-10.

CARRILLO Alday, Salvador "El Reino de los cielos", Medellín 11/43 (1985) 308-330.

CARRÓN, Julián. "Bienaventurados los que tienen hambre y sed de justicia porque ellos serán saciados", Communio - Internacional 6 (1990) 508-520.

CARVALHO, Marcello de “Abba - A oração de Jesús”, Convergência 192 (1986) 236-241.

CARVALHO Azevedo, Marcelo de "En Ten nombre", Convergência, 156 (1982) 460

CASALIS, Georges "Jesús: ni vencido ni Monarca Celestial. La Cruz es el punto culminante de la auténtica solidaridad", Christus 464 (1974) 12-14.

CASTELLI, Ferdinando "El Cristo de Nikos Kazantzakis", Encuentro 54/55 (1990) 262-266.

CASTELLI, Ferdinando "Miguel de Unamuno ante Cristo, a la luz de su diario íntimo", Encuentro 34 (1984) 96

CASTELLI, Ferdinando "Miguel de Unamuno frente a Cristo, a la luz de 'El Cristo de Velázquez”, Encuentro 35 (1985) 90-94.

CASTILlO, Alfonso s.j. "Confesar a Cristo el Señor y seguir a Jesús”, Christus 481 (1975) 19-31.

CASTILLO, Alfonso s.j. "Jesucristo” Christus, 534 (1980) 40-42.

CASTILlO, Alfonso s.j. "Jesús, hombre en crisis", Christus, 482 (1976) 15-21.

CASTILlO, Alfonso s.j. "Tema Joánico. Cristo Vida y Señor de la vida”, Christus, 458 (1973 - 1974) 21-25.

CASTILLO, Jose María "El discernimiento de Jesús y nuestro Discernimiento", Testimonio, 93/94 (1986) 5-14.

CASTILLO, José María “La Iglesia y el Reino de Dios”, Diakonia 31 (1984) 228-239.

CASTILLO, Tomás "El Vaticinio de Isaías. Hijo de una virgen”, Trípode, 169 (1980) 12-14

CASTRO, Baltasar "Cristo y la lucha de clases", Christus, 473 (1975) 56-59.

CASTRO Pallares, Salvador “Cristología” Libro Anual (1977- 1978) 161 -167.

CATALÁ, Toni "Seguir a Jesús pobre y humilde”, Sal Terrae 2 (1991) 102-114.

CERDA, Jorge "El Hijo del Hombre y Jesús de Nazaret”, Koinonía, 8 (1978) 4.

CESAR, José Vicent "Anthropos - Logos”, Actualização, 193-194 (1986) 3-26.

CHAMBERLAIN, Francisco "Caminar hoy en la fe: por las huellas del crucificado”, Páginas, 100 (1989) 47-56.

CHAMBERLAIN, Francisco "Testigo de la resurrección desde la cruz", Páginas 61 (1984) 2.

CHAMBERLAIN, Francisco "Apuntes para una Cristología de San Lucas", Páginas, 34 (1981) 9-15

CHANTRAINE, Georges “¿De qué hablamos cuando decimos 'Resurrección del Señor'?”, Communio 16 (1986) 64-69.

CHARBEL, Antonio "Cruz y Resurrección único misterio salvífico”, Estudios Teológicos, 7 (1977) 102. 
CHARBEL, Antonio "Os evangelhos da infancia de Cristo" Revista de Cultura Bíblica, 9 (1985) 156- 159.

CHECA, Rafael "Pasión de Jesucristo - Pasión del hombre", Senderos 34 (1989) 66-79.

CLAR "Seguir a Jesucristo en la Iglesia del continente" Clar, 7 (1984) 4.

CLEMENT, Oliver "El pobre como otro Cristo", Communio 12 (1985) 58-60.

CODINA, Víctor "Seguir a Jesús hoy en América Latina”, Testimonio 111 (1989) 82-89; Revista Vida Espiritual 97 (1989) 37-44.

COLLINS, Raymond "Los milagros en el Evangelio de Marcos" Actualidad Pastoral, 132 (1980) 93-95.

COLLINS, Raymond “Jesús, Hijo de Dios”, Actualidad Pastoral, 166 (1987) 31-35.

COMBLIN, Joseph "El clamor de Jesús y el clamor de los oprimidos", Pastoral Popular 4 (1985) 21-24. 41-59.

COMBLIN, Joseph "Jesús profeta”, Revista Eclesiástica Brasileira, 44 (1984)

COMBLIN, Joseph "La presencia universal del Reino de Dios y el sentido actual de la misión", Chile Misionero 2 (1983) 12; Chile Misionero 1 (1983) 16.

COMISIÓN TEOLÓGICA INTERNACIONAL "Teología - Cristología - Antropología", Sedoc 163 (1983) 7.

CONCHA Malo, Miguel o.p. "Una Cristología consciente de sus presupuestos", Christus, 511 (1978) 39-41.

CONCHA MALO, Miguel "Fundamentación histórico-teológica del anuncio de Jesucristo hoy", Libro Anual, (1977-1978) 141-155.

CONFERENCIA EPISCOPAL DE NICARAGUA, "Jesucristo y la Unidad de su Iglesia en Nicaragua", Tierra Nueva, 37 (1981) 78.

CONGRESO NACIONAL DE TEOLOGÍA IV, Colombia, "Jesucristo salvador y liberador", Theologica Xaveriana, 54 (1980) 3-210.

CONVENCIÓN EVANGÉLICA BAUTISTA ARGENTINA "Jesucristo la única esperanza", Pastoralia 8 (1982) 66.

COOK, Michael L. “¿Tuvo Jesús una 'Última Tentación’?”, Mensaje, 374 (1988) 473-476.

CORBIERE, Emilio “Jesucristo tiene la palabra”, Sir 122-123 (1990) 30-31.

CORBIN, M. "La sabiduría de la cruz”, Stromata, 3-4 (1980) 227-237.

CORDERO, Luis "El misterio del Corazón de Jesús", Revista Teológica Limense 1 (1982) 99.

COSTADOAT, Jorge "Evangelización de la cristología popular", Revista de Ciencias Religiosas, Vol. V (1998) 65-69.

COSTADOAT, Jorge "Características y alcances de la humanidad de Jesucristo” Teología y Vida, Vol. XXXVIII (1997) 163-174.

COSTADOAT, Jorge "La libertad de Cristo", Teología y Vida, Vol. XL (1999) $110-134$.

COSTADOAT, Jorge "La fidelidad de Jesús", en Cuadernos de Espiritualidad 131 (2002) 25-37.

COSTADOAT, Jorge "Interrogantes sobre la cristología latinoamericana", en Jesucristo, prototipo de humanidad en América Latina (Tercera reunión de la Comisión Teológica de la Compañía de Jesús en América Latina), México, 2001, 77-84. 
COSTADOAT, Jorge "La humanidad de Jesús. Un enfoque para la devoción al Sagrado Corazón”, Mensaje, 459 (1997) 32-36.

COSTADOAT, Jorge "Navidad, origen de la fantasía", Mensaje, 455 (1996) 10-12.

COSTADOAT, Jorge "De la Sagrada Familia a la familia humana", Mensaje, 495 (2000) 18-19

COSTADOAT, Jorge "Viernes Santo. Meditación sobre el fracaso", Mensaje, 447 (1996) 75-77.

COSTADOAT, Jorge "Padre de Jesús y Padre nuestro", Mensaje, 491 (2000) 55-58

COSTADOAT, Jorge "El pobre es Cristo", Mensaje, 469 (1998) 25-28.

COSTADOAT, Jorge "Jesús: Palabra de hombre, palabra de Dios", Cuadernos de Espiritualidad (CEI), 119- 120 (2000) 32-35.

COX B., Andrés "El Misterio de Jesus", Mensaje, 7/75 (1958) 436-442

CRB "A pratica missionaria de Jesus de Nazaré e dos seus discípulos", Convergencia 254 (1992) 369-376.

CROATTO, Severino "La dimensión política del Cristo liberador", Cristianismo y Sociedad, 13 (1975).

CROATTO, Severino "La Epifanía bautismal del Cordero Pascual: estructura literaria y teológica de Juan 1, 19-34", Cuadernos de Teología 3 (1983) 33.

CRUZ, Antonio "Seguimiento y anuncio de Jesús desde los pobres”, Páginas, 63-64 (1984) 34.

CUMMINGS George, “¿Quién dices que soy yo?”, Boletín Teológico, 8 (1982) 61.

DAMEN, Frans "Hacer teología de la Cruz en América Latina", Nuevo mundo, 35 (1988), 13-18.

DAMEN, Frans "Viernes Santo de América", Senderos, 34 (1989) 3-8.

DANEL, Janet Fernando "Crisis y praxis de Liberación, la verificación histórica del Logos cristiano", Christus 41 (1976), 41-45.

DANIELIÁN, Jorge "El sufrimiento humano: Cruz y Resurrección”, Cuadernos Franciscanos, 20 (1987), 8-16.

D’ANGELO, Marcos "La divinidad de Jesucristo en Aurelio prudencio", Revista Teológica Limense 18 (1984) 291-330.

DE BERULLE, Pedro "El nacimiento y la infancia de Jesús", Vida y Espiritualidad, 4 (9) (1988) 61-72.

DE BOER, Tejeerd "Hacia el tercer milenio después de Cristo", Teología en comunidad 4 (1989) 33- 43.

DE CARVALHO, Marcello “A Oração de Jesús, referencial da nossa Oração”, Convergencia, 21 (191) (1986) 159-165.

DE CASTRO, Juan "Camino de nueva evangelización a partir de Cristo Plenitud del hombre", Teología y Esperanza 1 (1991)10-13.

DE COL, Antonio "Las Bienaventuranzas. Catequesis desde A. Latina", Didascalia, 385 (34) (1985) 4-30.

DE DOBIZYNSKI, Estanislao "Jesús ante el poder de las tinieblas", Didascalia 45 (1991) 4-17.

DE FERRARI, José Manuel "El rechazo de Dios a la Cruz", Pastoral popular 43 (1992) 216, 10-13; Diakonia 16 (1992) 61- 68.

DE GUCHTENEERE, Pedro "Curaciones de Jesús, Respuesta de la Fe", Páginas, 47 (1982) 2. 
DE LA TORRE, Jesús “Jesús el comunicador”, Nuevo Mundo, 154 (1992) 51-60.

DE LA TORRE Jesús "Los pueblos indígenas al encuentro de Jesucristo", Iter, 2 (1992) 61-80.

DE LA SERENA, Eduardo "La Cruz y el Crucificado en I Cor", Revista Bíbli$c a, 49$ (28) (1987) 209-213.

DE MARGERIE, S. "Reflexiones sobre las tendencias actuales en Cristología", Tierra Nueva, XII/47 (1983) 36.

DE PRADO, Consuelo "Mi reino no es de este Mundo”, Páginas 58 (1983), 1.

DE PRADO, Consuelo "Seguir a Jesús", Páginas 10 (1985) 71-72 .

DE SCHRIGUER, Silvio "Conocer a Cristo", Criterio, LVII (1984) 413.

DE WITT, Hans "Buscando entre los muertos al que vive", Pastoral Popular 186 (1988), 17-19; Solidaridad 12 (1990), 23-25.

DEL VALLE, Luis G. "Liberación, Salvación, redención", Christus 45/534 (1980) 44-45.

DELANEY, Eugenio "La Teología de la Cruz en y para América Latina", Senderos, 31 (1988) 26 - 35.

DÍAZ, Juan "Privilegiar el encuentro personal con Jesucristo", Testimonio, 105-106 (1988), 39-43.

DÍAZ MATEOS, Manuel "Jesucristo: ayer, hoy y siempre", Christus, 58 (1993) 46-56.

DÍAZ MATEOS, Manuel "Cristo no me llamó a bautizar, sino a evangelizar", Revista Teológica Limense, 25 (1991) 343-367.

DÍAZ MATEOS, Manuel “Te reconocemos, Señor, al partir el pan”, Diakonia, 8/49 (1989) 45-74; Christus, 54 (1989), 55-56; Páginas, 13 (1988) 27-48.

DÍAZ MATEOS, Manuel "En Cristo hay humanidad nueva", Páginas, 40 (1981), 2.

DÍAZ MATEOS, Manuel "El oficio de consolador de Cristo", Cuadernos de Espiritualidad, 22 (1982), 3.

DÍAZ MATEOS, Manuel “Oración del Señor, oración del Reino”, Fe y Solidaridad, 42 (1982); Páginas, 41 (1981), separata.

DÍAZ VALENCIA, Héctor "Jesús ante una nueva lectura de la Biblia. Preámbulos de la Pasión y muerte de Jesús", Christus, 42 (1977) 38-43.

DOGWIN, Paul Dominique "Cruz-Liberación-Éxodo-Reino de Dios", Revista Teológica Limense, XVI/1 (1982), 89.

DOLAN, Roberto "Cristo pobre acompaña a sus hermanos", Christus, 39 (1973) 34-36.

DONNEL, J "Jesús y el Espíritu”, Boletín de Espiritualidad, 103 (1987) 1-9.

DRI, Rubén "La conflictividad en la vida de Jesús", Servir, 85 (1980), 51-69.

DRI, Rubén “Jesús y la política”, Servir, 103 (1983), 367.

DUCOURTRAY, A. "Jesús nunca dijo...", Boletín de Espiritualidad, 97 (1986) 21-23.

DUFOUR, L. - MACKENZIE “Jesús e os Escravos”, Revista de Cultura Bíblica VII /28 (1988) 3.

DUQUE, Gilberto "Día Quinto-Prima. donde se produce una fraterna discusión sobre la pobreza de Jesús", Theologica Xaveriana, 36 (1986) 101-113.

DUSSEL, Enrique "El Reino de Dios y los pobres", Servir, XV (1979) 517-550. 
EDWARDS, F. "La búsqueda del rostro de Cristo en la vida Benedictina". Carisma, 29 (1991) 127-132.

ELLACURÍA, I. "Las bienaventuranzas como carta fundacional de la Iglesia de los pobres". Diakonía, 19 (1981) 56.

ELLACURÍA, I. "Dimensión política del mesianismo de Jesús", Fe y Solidaridad, 41, (1982).

ELLACURÍA, I. “Juicio político contra Jesús”, Solidaridad, 2/12 (1980) 15-20.

ELLACURÍA, I. "Los pobres, lugar teológico en América latina”, Diakonía, 21 (1982) 41.

ELLACURÍA, I. "El pueblo crucificado, ensayo de sotereología histórica". Revista Latinoamericana de Teología, 6 (1989) 305-333.

ENRÍQUEZ, J.R. "Dios, Cristo y Cíclope en la obra de Revueltas", Christus 54/ 629 (1989) 27-31.

EPISCOPADO DE AMÉRICA LATINA. "Gesucristo, vita e esperanza del' América Latina”, Santo Domingo, Sial XV (1992), 16-17.

FERNÁNDEZ, David "Cristología y Cultura de Masas en 'Minimilagros",, Christus, 46 (542) (1981) 9-21.

FERRARI, José Manuel "Elementos cristológicos del Documento de Puebla" Servicio, 38 (1979) 1 - 4.

FERRARO, Benedito "Cristología a partir de América Latina. Presupuestos" Reb. 48 (1988) 283 - 309.

FERRANDO, Miguel Ángel "El mensaje de Jesús a una sociedad violenta" Carisma, 18 (1986) 28 - 43.

FERRANDO, Miguel Ángel "Ver a Jesús, un aspecto fundamental de la Cristología del Cuarto Evangelio", Carisma 29 (1991), 91-106.

FERRARA, Ricardo "La verdad sobre Cristo y el Hombre", Sedoi Documentación, 39 (1979) 1 - 21.

FERRARO, Benedeto. "Jesús e os marginalizados do seu tempo", Vida Pastoral, 117 (1988), 9.

FEVARO, Benedeto "Cristología no documento de Santo Domingo", Rev. de cultura teológica, 1/4 (1993) 83-88.

FIORITO, M.A. "Cristo Resucitado y Glorioso en nuestra Oración y nuestra Acción”, Boletín de Espiritualidad, 60 (1979), 18- 35.

FIORITO, M.A. “La Mirada del Señor”, Boletín de Espiritualidad, 101 (1986) 12- 17.

FISHER, Eugene "El cristianismo en los primeros tiempos", Medellín, 14 (54) (1988) 217- 230.

FISHER, Joaquim "Jesus Cristo a unica palavra de Deus que devemos ouvir", Estudios Teológicos, 24 (1984) 98.

FONTAINE, Pablo "El corazón de Cristo Liberador", Servicio, 78 (1983) 240.

FONTAINE, Pablo “Con Jesús en la cruz”, Testimonio, 111 (1989) 23- 29; Revista Vida Espiritual, 97 (1989) 45 -51.

FOULKES, Ricardo "Mi reino no es de este mundo. Estudio exegético de Juan 18, 36" Vida y pensamiento, III (1- 2) (1982) 43.

FRESNO, Juan Francisco "La resurrección de Cristo, esperanza nuestra", Iglesia de Santiago, 158 (1984) 1.

GALILEA, Segundo "La actitud de Jesús ante la política”, Servir, 41-42 (1972) 491. 
GALILEA, Segundo "El camino de la cruz", Diakonía, (1983) 201; Senderos 31 (1988), 60-69; Testimonio 125 (1991) 5-10.

GALILEA, Segundo "El Cristo oculto del hinduismo" Medellín, 43 (1985) 428-432.

GALILEA, Segundo "Cristología y ortopraxis cristiana", Christus, 458 (19731974) 16-20; Teología y Vida 1 (1974) 47-56.

GALILEA, Segundo "El encuentro con Cristo en el prójimo" Carisma, 29 (1991) 107-116.

GALILEA, Segundo "Jesús como formador de discípulos" Servicio, 82 (1984) 51.

GALILEA, Segundo "Jesús y la liberación de su pueblo" Mensaje, 221 (1973) 351-356; Christus, 449 (1973) 59-62.

GALILEA, Segundo "Seguimiento de Cristo y evangelización”, Testimonio, 59 (1980) 40-46.

GALLEGO, Andrés "Lavar los pies hoy", Pastoral Andina, 83 (1992) 20-21.

GALLI, Carlos "Jesucristo: revelador del amor de Dios y de la dignidad del hombre", Nexo, 16 (1988) 16-24.

GALLO, Luis "La salvación en Cristo hoy", Didascalia, 361 (1983) 4.

GALOT, Jean "El Cristo de siempre y para siempre. Consideraciones cristológicas", Medellín, 70 (1992) 212-226.

GALOT, Jean "Cristo da experiencia, Cristo do dogma", Cultura e Fe, 8/24 (1984) 13

GALOT, Jean "Jesús, revelación del absoluto", Medellín, 7/26 (1981) 147-159.

GALOT, Jean "Seguir a Cristo", Cuadernos Monásticos, 78 (1986) 328-338.

GARCÍA, Antonio "Meditación sobre el crucificado", Cuadernos de espiritualidad, 21 (1982) 18-24.

GARCÍA, José "Viernes Santo, meditaciones sobre el crucificado", Diakonía, 33 (1985) 52.

GARCÍA, José "Ser hombres del Espíritu, o cómo vivir 'al aire de Jesús", Diakonía, 10/39 (1986) 245-259.

GARCÍA MURGA, José "Creo en Jesús el hijo de Dios”, Razón y Fe, 208 (1983) 50

GARCÍA V., Alberto "Redención de Cristo y corredención de María", Mikael, 33 (1983) 37.

GARABAY, Xavier "La práctica de Jesús" (resumen del libro de Hugo Echegaray), Christus, 47/552 (1982) 32-38.

GASTALDI, Néstor "La cruz de Cristo mirada desde antes de la resurrección", Didascalia, 45/439 (1991)18-25.

GASTALDI, Néstor, "La cruz de Cristo mirada desde la resurrección", Disdascalia 45/444 (1991) 4-10.

GASTALDI, Néstor “¿Jesús de Nazareth era Hijo de Dios? ... ¿pero de qué Dios?" Didascalia 44/434 (1990) 4-8.

GASTALDI, Néstor "El Jesús de nuestra catequesis:¿un superman o un hombre con nosotros?", Didascalia, 432 (1990) 4-8.

GEBARA, Ivonne “Cristología fundamental”, Reb, 190 (1988) 259-272.

GIL, D. "La ira de Jesús", Boletín de espiritualidad, 110 (1988)1-6. 
GIL, Herminio "Sentido de la redención en la actual teología de la cruz", Christus, 583-584 (1985) 33-38.

GIL, Herminio "Exigencias de la actual Teología de la Cruz", Senderos, 31 (1988) 49-59.

GIRALDO R, Néstor "El problema del Jesús histórico", Cuestiones teológicas, 26 (1983) 5.

GIRARDI, Victorino, "La Teología de la Cruz en América Latina”, Christus, 583/584 (1985) 39- 43.

GODOY, Daniel "Pasión, muerte y resurrección de Jesucristo: una relación desigual", Pastoral popular, 191 (1989) 13-16.

GODOY, Daniel "Pasión, muerte y resurrección de Jesucristo", Pastoral Andina, 76 (1991) 21-26.

GOMES DE SOUSA, Filho Severino "Jesucristo sinal de comunicação entre Deus la humanidade", Grande Sinal, 44 (1990) 655-661.

GÓMEZ, José "Racionalidad de la Opción por el Dios de Jesús de Nazaret", Encuentro, 36 (1985) 163-167.

GONZÁLEZ, Carlos Ignacio “Antecedentes de la Cristología Arriana en el s. III”, Medellín, 16/63 (1990) 315-361.

GONZÁLEZ, Carlos Ignacio "Herejías Cristológicas en la Comunidad del Nuevo Testamento", Medellín, 15/55 (1988) 386-427.

GONZÁLEZ, Carlos Ignacio "La Tradición de la Cristología Apostólica en el SII", Medellín, 15/57 (1989) 15-69.

GONZÁLEZ, Carlos Ignacio "La Cristología del Concilio de Nicea”, Medellín, 17/65 (1991) 5-54.

GONZÁLEZ, Carlos Ignacio "Postnicea: La atormentada recepción de la Cristología Niceana”, Revista Teológica Limense, 24/3 (1990) 343- 382.

GONZÁLEZ FAUS, José Ignacio "La buena noticia de Jesús ante la mala noticia de un mundo violento", Páginas, 91 (1988) 87-100.

GONZÁLEZ FAUS, José Ignacio "La fe en Jesucristo, raíz, plenitud y compañera de la liberación humana”, Christus, 506 (1978) 10-20 y 62.

GONZÁLEZ FAUS, José Ignacio "De la "indiferencia" al "tercer grado de la humildad", notas para una cristología de libertad", Revista Latinoamericana de Teología, 8/22 (1991)39-50.

GONZÁLEZ FAUS, José Ignacio "La "Cristología desde América Latina” de Jon Sobrino", Christus, 43/511 (1978) 30-38.

GONZÁLEZ FAUS, José Ignacio "Lo imposible se hace posible en Jesucristo", Pastoral Misionera, (1983) 422.

GONZÁLEZ FAUS, José Ignacio "Los milagros de Jesús (II). El mensaje de los Hechos", Mensajero, 725 (1988) 27-30.

GONZÁLEZ FAUS, José Ignacio "La opción por el pobre, elemento indispensable para interpretar la divinidad de Jesús", Christus, 45/540 (1980) 44-47.

GONZÁLEZ FAUS, José Ignacio “¿Qué Dios se nos revela en Jesucristo?”, Diakonía, 5/17 (1981) 23-38.

GONZÁLEZ FAUS, José Ignacio "El seguimiento de Jesús a partir de los desafíos y respuestas", Cuadernos de Espiritualidad, 18 (1981) 24-33. 
GONZÁLEZ, L. "Preguntas de Jesús (I)”, Boletín de espiritualidad, 98(1986) 20-23; 108 (1987) 20-22.

GONZÁLEZ M., Luis “Jesucristo, sembrador de justicia”, Christus, 449 (1973) 12-15.

GONZÁLEZ R., José María "El proyecto de Jesús frente a la sociedad humana", Signo 63 (1983) 28.

GONZÁLEZ, Antonio "El anuncio del reinado de Jesús, el Mesías”, en Comisión Teológica de la Compañía de Jesús en América Latina, Jesucristo, prototipo de humanidad en América Latina, Tercera Reunión, Obra Nacional de la Buena Prensa, Ciudad de México, 2000, pp. 129-158.

GORGULHO, Gilbert "O caminho e o seguimento de Jesús", Rev. Eclesiástica Brasileira (Cuadernos de estudios bíblicos 2) 174 (1984) 25.

GRACIO DAS NEVES, Rui Manuel "El Dios de Jesús imperativo de justicia y liberación", Biblia y Fe, 17/ 50 (1991) 52-97.

GUARDINI, Romano "Cristo entre nosotros", Boletín de espiritualidad 84 (1983) 19.

GÜELL, Pedro (C. Precht- P. Sähli) "La pascua de Jesucristo y la ley de la vida", Mensaje 292 (1980) 463-468.

GUERRA, Augusto "Resucitar a los sacrificios de este mundo. Cristología de Liberación", Revista de Espiritualidad, 47/186 (1988) 91-119.

GUERRERO, Alfonso "El Cristo popular, crítica y perspectiva", Nuevo Mundo, 93 (1980) 260-264.

GUERRERO, Alfonso "Jesús: el poder que es Dios", Nuevo Mundo, XVIII/107 (1982) 449.

GUERRERO, Alfonso "Proseguir a Jesús”, Nuevo Mundo, 137 (1988) 241-249.

GUERRERO, José María "La pobreza de Jesús, camino de solidaridad", Testimonio, 111 (1989) 61-71.

GUERRERO, José María “Anunciar eficazmente a Jesucristo hoy”, Testimonio, 89 (1985) 14.

GUERRERO, José María "Dedicarse por entero a la causa de Jesús", Revista Vida Espiritual, 97 (1988) 13-15.

GUERRERO, José María "Y Él nos amó hasta el extremo", Testimonio, 117 (1990) 35-44.

GUERRERO, José María "Jesús como animador de la comunidad de los doce", Testimonio, 81-82 (1984) 9.

GUEVARA, R. "Dios del destino y Jesucristo en un suburbio", Christus, 489 (1976) 47-50.

GUTIÉRREZ, Gustavo “Jesús y el mundo político”, Teología y Vida, 4 (1973) 269-271.

GUTIÉRREZ. Gustavo "En busca de los pobres de Jesucristo" Mensaje, 302 (1981) 504-514.

HAMMES, Erico, "Cristología e seguimento en Dietrich Bonhoeffer", Teología comunição, 21/94 (1991) 497-516.

HANSEN, Theo "El lugar de la resurrección de Cristo en la historia de salvación”, Teología y Vida, 11/2 (1970) 75-84.

HARGREAVES, H. J. "O que Cristo significa en minha Vida", Actualização, 20/228 (1990) 1093-1098. 
HAYS, R.B “Cristología y ética en Gálatas. La ley de Cristo”, Selecciones de Teología, 28/110 (1989) 125-136.

HELEIVA, Giovanni "Para mí vivir es Cristo", Vida Espiritual, 78, (1983) 35.

HELEWA, Juan "La nueva alianza en Jesucristo", Vida Espiritual, 83/84 (1986) $11-31$.

HERNÁNDEZ PICO, J. "El método teológico latinoamericano y normatividad de Jesús histórico para la praxis política mediada por el análisis de la realidad", Estudios contemporáneos, 322-323 (1975) 446-454.

HERNÁNDEZ PICO, J. "Una exaltación que olvida la agonía”, Christus, 536/ 537 (1980) 83-85.

HERRERA, César "Jesucristo es el mismo ayer hoy y siempre. Reflexiones de hermenéutica bíblica”, Medellín, 18 /70 (1992) 183-211.

HOEFFERKAMP, Roberto "La ética del reino de Dios en América Latina", Vida y Pensamiento, 1 (1985) 41-42.

HOFFMANN, Norbert, ss.cc "El misterio de la 'sustitución' como centro del Cristianismo", Tierra Nueva, 9/ 33 (1979) 83-93.

HOOG, P. M "Ese hombre feliz que fue Jesús", Boletín de Espiritualidad, 107 (1987) 11-16.

HOURTON, Jorge "En busca de los pobres de Jesucristo", Pastoral Popular, $44 / 226$ (1993) 23-25.

HUALDE, Antonio Carlos "La Iglesia es el sacramento de Cristo", Nuevo Mundo, 16/92 (1980) 167-174.

HUERTA, Eduardo "La realeza de Jesús en el cuarto evangelio", Teología y Vida, 32/3 (1991) 213-220.

HUNEEUS COX, Alejandro "La historia de Adán en la teología cristiana", Revista Católica, 1018 (1970) 5860-5867.

HUNEEUS COX, Alejandro "El reinado de Jesucristo", Revista Católica, 1019 (1971) 5950-5957.

IDIGORAS, José Luis. "Nuestra imagen de Jesucristo", Cuadernos de Espiritualidad, 26 (1983) 30.

IDIGORAS, José Luis “La historia bíblica frente a las 'realizaciones' del Reino”, Medellín, 11 (1985) 331-354.

IRARRÁZABAL, Diego "La cruz de un Pueblo crucificado", Pastoral Popular, 1 (1981) 11; Mensaje Iberoamericano, 209 (1983) 11.

IRARRÁZABAL, Mario “Mi experiencia de Cristo”, Mensaje, 296 (1981) 20-21.

IRIARTE, Lázaro “Misericors dei Filius”, Cuadernos Franciscanos 17 (1984) 49.

JARA, Víctor H. "El Cristo del alma franciscana”, Carisma, 29 (1991) 133-140.

JARAMILLO C., Luciano “Jesús y las mujeres”, Digesto Familiar, 171 (1988) 23-2.

JEREMÍAS, J. "La novedad del Reino". Extractos de "Teología del Nuevo Testamento", Cuadernos de Espiritualidad, 17 (1981) 41-43.

JIMÉNEZ, Pablo "Exégesis y Exposición de Efesios 2. Cristo es nuestra Paz", Vida y Pensamiento, 1 (1988) 18-24.

JIMÉNEZ LIMÓN, Javier s.j. “CCómo podría, mi Señor, creer en ti?”, Christus, 587 (1985) 15-18.

JIMÉNEZ LIMÓN, Javier s.j. "Sobre la Cristología de Juan Luis Segundo", Christus 49 (Ago. 1984) 57-61. 
JIMÉNEZ LIMÓN, Javier s.j. "Una Cristología para la conversión en la lucha por la justicia", Christus, 511 (1978) 44-54.

JIMÉNEZ LIMÓN, Javier s.j. “Jesús y el poder”, Christus, 492 (1976) 46-55.

JIMÉNEZ LIMÓN, Javier s.j. "Lectura científica y/o simbólica del Reino", Christus, 552 (1982) 29.

JIMÉNEZ LIMÓN, Javier s.j. "Meditaciones sobre el camino de Jesucristo", Christus, 458 (1973-1974) 26-29.

JIMÉNEZ LIMÓN, Javier s.j. "Reino de Dios”, Christus, 534 (1980) 55-56.

JOBERT, Philippe "La unidad del Corazón de Jesús y el de María según San Juan Eudes", Tierra Nueva, 65 (1988) 73-78.

JSERN, Juan S., Mons. “El Reinado en el año Santo”, Reinando Juntos, 96 (1983) 3. JUAN PABLO I “Carta a Jesucristo”, Senderos 1(1978) 61-65.

JUAN PABLO II, "Carta Encíclica Redemptor Hominis", Criterio, 1809 (1979) 163-181; DIC Boletín, 11-12 (1979); Revista Católica, 1043 (1979) 25-55.

JUAN PABLO II "El corazón traspasado en la cruz es el fruto del amor eterno de Dios", Tierra Nueva, 80 (1992) 65-70.

JUAN PABLO II “As definicões Cristológicas dos Concilios e a fe da Igreja de Hoje", Cultura e Fe, 41 (1988) 82-85.

JUAN PABLO II “Jesucristo nuestro camino", Vida Pastoral, 128 (1984) 1.

JUAN PABLO II “O liberador do homen”, Sedoc, 121 (1979) 1149.

JUAN PABLO II "El mundo de la cultura, el hombre y Jesucristo", Mensajero, 66/698-699 (1985) 11-13.

JUAN PABLO II "Presentar a Jesús como político no es evangélico", Trípode, 157 (1979) 4-7.

JUAN PABLO II "Reconciliación con Dios y con los hombres en Cristo", Vida y Espiritualidad, 13 (1989) 135-138.

JUAN PABLO II "Redemptoris Missio", Clar, 3 (1991); Chile Misionero 127 (1991) 5-38; DIC, 950 (1991) 91-101; DIC 951 (1991) 10-111; DIC, 956 (1991) 113-126; Sedoc, 226 (1991) 652-703.

JUAN PABLO II “Seguir a Jesús”, DIC, 855 (1989) 241-245.

JUAN PABLO II "El Señor es mi pastor", Boletín de espiritualidad, 127 (1991) 1-10.

JUAN PABLO II "Las últimas palabras de Jesús en la Cruz: 'Ahí tienes a tu madre'...”, Vida y Espiritualidad, 11 (1988) 121-125.

JUAN PABLO II "El corazón traspasado en la cruz es el fruto del amor eterno de Dios", Tierra Nueva, 80 (1992) 65-70.

KAPKIN, David "Cuestiones en torno a la pasión, muerte y resurrección de Jesús”, Cuestiones Teológicas 14 (37) (1987) 25-56.

KAPKIN, David "Un tal Jesús, una evaluación crítica”, Tierra Nueva, XI/40 (1982) 30-36.

KARLIC, Estanislao "La Cristología en Puebla", Actualidad Pastoral, XII/126 (1979) 58-59.

KARLIC, Estanislao "Jesucristo ayer, hoy y siempre en América Latina”, Medellín 19/73 (1993) 13-34.

KÄSEMANN, Ernest "El reinado escatológico de Dios", Actualidad Pastoral Argentina, XIII/ 133 (1980) 217-221. 
KELLY, James “Un himno sobre Cristo”, Stromata, 36 (1980) 293-299.

KLOPPENBURG, Boaventura "A conciencia de Jesus Segundo Leonardo Boff”, Actualizacão, XV (179-80) (1984) 511.

KLOPPENBURG, Boaventura "La situación de la cristología en América Latina”, Medellín, 6 (23) (1980) 374-387.

KONINGS, Johan "Jesus ou os pobres", Perspectiva Teológica, 25 (66) (1993) 149-162.

KONINGS, Johan "A memoria de Jesus e a manifestacão do pai no quarto evangelho", Perspectiva Teológica, 20 (15) (1988) 177-200.

KRAUTLES, Erwin "Jesús el Cristo: onten hoye e sempre", Convergencia, 27 (254) (1992) 353-368.

KRÜGER, René "Humilde montado en un burrito, Mateo 21, 1-11" Revista Bíblica, 53/46 (1992) 65-83.

KRÜGER, René "El Magníficat de Lucas 1, 46-56”, Cuadernos de Teología, 9/ 1 (1988) 77-83.

KUNH, Fernando "Introducción al análisis de la Cristología fundamental de Juan Luis Segundo", Revista Anatellei, No 1 (Junio 1999), Córdoba, Argentina.

LAMBRECHT, Jean "Es necesario que Cristo reine", Communio, 4/16 (1986) 46-54.

LAURENTIN, René “Jesús y las mujeres: una revolución ignorada”, Páginas, 46 (1982) separata.

LEGGETL, Pablo “¿Platón o Jesucristo? Presupuestos filosóficos en la teología sistemática", Vida y Pensamiento, 1-2 (1983) 2.

LEPELEY, Joaquín "El corazón traspasado, fuente de reconciliación”, Vida y Espiritualidad, 3 (1987) 9-26.

LEPELEY, Joaquín "Corazón de Cristo, revelación y entrega al hombre, de Dios", Tierra Nueva, 15 (1986) 90-95.

LEROY, M. V. "Pobreza de Cristo-Pobreza de la Iglesia", Communio, 1 (1982) 18.

LEVORATTI, Armando "La sombra del Galileo: un comentario", Revista Bíblica, 52 (1990) 193-233.

LEVORATTI, Armando "Milagros de Jesús y teología del milagro", Revista Bíblica, 50 (1988) 1-32.

LECLERQ, Jean "El problema de las clases sociales y la Cristología en San Benito”, Cuadernos Monásticos, 57 (1981) 205.

LIBANIO, João Batista "Jesús Cristo. Onten hoje esempre", Convergencia, 28 (1992) 77-91.

LINO YÁNEZ, José “Jesús, el vino nuevo”, Testimonio, 117 (1990) 45-54.

LLONA, Ma. Angélica "Jesús: modelo y fuente de solidaridad universal", Mensaje, 421 (1993) 341-346.

LOCKMANN, Paulo "A caminada do Messias Jesus. Um novo exodo", Revista Eclesiástica Brasileira, 174 (1984) 18.

LOCKMANN, Paulo "La crítica de Jesús", Ribla, 10 (1991) 83-90.

LOIS, Julio "Para una espiritualidad del seguimiento de Jesús", Diakonía, 10/ 29 (1986) 260-276.

LONA, Horacio "Una propuesta de anuncio cristológico", Didascalia, 41/405 (1987) 14-16. 
LONGO, Carlos "Cristo es nuestra ley: su mandamiento es amar", Didascalia, 369 (1984) 24.

LÓPEZ, Francisco "Reino de Dios y socialismo", Christus, 502 (1977) 42-47.

LÓPEZ, Francisco "Seguimiento de Jesús en América latina”, Christus, 645/ 646 (1991) 45-50.

LÓPEZ, Víctor Manuel “Creemos en Jesucristo”, Vida Pastoral, 17 (1989) 40-43.

LÓPEZ MARTÍNEZ, Nicolás "El Espíritu del Corazón de Cristo", Tierra Nue$v a, 49$ (1984) 55.

LÓPEZ RIVERA, Francisco "La pasión de Jesús de Nazaret, Hijo de Dios", Christus, 583-584 (1985) 23-28.

LÓPEZ TRUJILLO, Alfonso "La Cristología, perspectivas actuales", Сommunio, III/ 5 (1983) 51.

LÓPEZ TRUJILLO, Alfonso "El mensaje liberador, desde Cristo, de Juan Pablo II", Communio, III/ 17 (1987) 27-34.

LORING, Salvador “¿Por qué me buscabais? ¿No sabíais que tengo que estar en las cosas de mi Padre?", Estudios Paraguayos, IX/ 2 (1981) 389.

LÖSCHKE, Eberto "La economía del Reino”, Pasos, 13 (1987) 1-5.

LUCIANI, Albino "Carta a Jesucristo", Senderos, 1 (1978) 61-65.

LYONNET, St. “...Salió sangre y agua (Jn 19, 34)”, Boletín de Espiritualidad, 111 (1988) 12-22; Tierra Nueva, 18 (1989) 62-69.

MACANEIRO, Marcelo "Espiritualidad reparadora do coração de Jesus hoje", Convergencia, 263 (1993) 314-321.

MACANEIRO, Marcelo "Espiritualidad do coração de Jesus e reparação na AL", Grande Sinal, 46 (1992) 323-335.

MACANEIRO, Marcelo "Praxis histórica partiendo del corazón de Jesús", Tierra Nueva, 73 (1990) 83-94.

MACCISE, Camilo "Cristo presente en los hermanos", Clar, 23 (1985) 4-23.

MACCISE, Camilo "Espiritualidad del seguimiento de Jesús", Testimonio, 111 (1989) 14-22.

MACCISSE, Camilo "Espiritualidad del seguimiento de Jesús", Revista de Espiritualidad 187 (1988) 207- 231.

MACCISE, Camilo "Formamo um so corpo em Cristo", Convergencia, 125 (1979) 405-412.

MACCISE, Camilo "Vida en el Espíritu de Jesús en América Latina", Christus, 645/646 (1991) 38-44.

MADERA VARGAS, Ignacia “El seguimiento de Jesús”, Teológica Xaveriana, 73 (1984) 471-492.

MAIA, Pedro Américo “Amar Jesús”, Actualização, 211 (1988) 63-76.

MAIA, Pedro "Jesús na tradição da Igreja. Suitese da Cristologia S. B. Sesbouë”, Actualização179/180 (1984) 527.

MAIA, Pedro "Loucos por amor a Cristo", Actualização, 206 (1987) 99-128.

MAIA, Pedro “Assim fui Jesús. Un libro de José A. de Sobrino", Actualizaçao, 219 (1989) 235- 268.

MANRÍQUEZ, Rodrigo "Espiritualidad desde el dolor y la Pascua de Cristo", Teología y Esperanza, 7 (1991) 28-33.

MANSELLI, Raúl "San Francisco, de la pasión del hombre en la pasión de Cristo" Cuadernos franciscanos, 67 (1984) 131. 
MARCHESI, Giovanni "Elementos históricos da trascendencia de Jesús. A sua autoridade", Cultura e fe, 28 (1985) 9-24.

MARCHESI, Giovanni "A historicidade de Jesus e o seu conhecimiento", Cultura e fe, VII/27 (1984) 9.

MARGERIE, Bertrand "San León Magno, exegeta litúrgico de los misterios de Cristo reunidos en la Iglesia”, Cuadernos Monásticos, 106 (1993) 329-364.

MARGERIE, S.T. "Reflexiones sobre las tendencias actuales en cristología", Tierra Nueva, 47 (1983) 36.

MARION, Jean Luc, "La crisis y la cruz", Communio, 2/9 (1984) 51-64.

MARITAIN, Jacques "Bienaventurados los que sufren persecución”, Сотmunio, 23 (1990) 14-18.

MARLÉ, René “Jésus devant la conscience moderne par un "théologien de la liberation", Études 370, Nº 6 (1989) 831-836.

MARSHALL, Guillermo "Los ciegos ven, los cojos andan", Mensaje, 228 (1974) 179.

MARSHALL, Guillermo "La entrada a Jerusalén”, Mensaje, 244 (1975) 528.

MARSHALL, Guillermo "Jesús exorcista”, Mensaje, 229 (1974) 256-257.

MARSHALL, Guillermo "Jesús y la familia”, Mensaje, 244 (1975) 527.

MARSHALL, Guillermo "La luz que juzga", Mensaje, 242 (1975) 396.

MARSHALL, Guillermo "La palabra se hizo carne", Mensaje, 250 (1976) 305-306.

MARSHALL, Guillermo "Los panes en el desierto", Mensaje, 231 (1974) 380.

MARSHALL, Guillermo “La pasión según San Juan”, Mensaje, 247 (1976) 121-122.

MARSHALL, Guillermo “¿Por qué hablas en parábolas?”, Mensaje, 230 (1974) 313-314.

MARSHALL, Guillermo "La vida triunfa sobre la muerte", Mensaje, 243 (1975) 458.

MARTI BAGUE, Juan Antonio "Bultmann y su aportación a la cristología", Senderos, 16 (1983) 72.

MARTENSEN, Hans "Martín Lutero, testigo de Jesucristo" Actualidad pastoral 150 (1983) 383.

MARTÍN, Santiago "Cristo en San Francisco", Revista de Espiritualidad, 186 (1988) 65-89.

MARTÍNEZ, Ángela "María, fiel compañera de Jesús", Revista de Vida Espiritual, 97 (1989) 61.

MARTÍNEZ, Agustín “La Cruz camino de liberación”, Testimonio, 117 (1990) 55-60.

MARTÍNEZ, Casimiro “Dejarlo todo para estar con Él”, Testimonio, 83 (1984) 51.

MARTÍNEZ, María Ángeles "La eucaristía: Dios hecho pan”, Testimonio, 117 (1990) 69-76.

MARTINI, Carlo M. "En el principio la palabra”, Testimonio, 119 (1990) 63-75.

MARTINI, Carlo M. "Crisis en el ministerio de Jesús", Boletín de espiritualidad, 135 (1992) 15-22.

MARTINI, Carlo M. "Jesús forma a sus discípulos”, Boletín de espiritualidad, 90 (1984) 1.

MARTINI, Carlo M. "Pasión de Pablo, pasión de Cristo", Boletín de espiritualidad, 94 (1985) 13-23. 
MARTINI, Carlo M. "Yo estaré con ustedes", Boletín de espiritualidad, 22 (1982) 16

MARTINI, Carlo M. "Yo estaré con ustedes", Boletín de espiritualidad, 88 (1984) 1 .

MARTINI, Carlo M. "La pasión según San Juan", Cuadernos de espiritualidad, 21 (1982) 12-13.

MARTINI, Uwe "La práctica de los resucitados o breves reflexiones". Xilotl, 7 (1991) 43-48.

MARTÍN, Carlos María "Coraje de David- coraje de Jesús" Boletín de espiritualidad 142 (1993) 13- 23.

MARTINS, Antonio Henrique C. "O simbolismo da porta e a mediação de Cristo", Grande Sinal, 42 (1998) 677-682.

MARTINS TERRA, Joãn "Significado del sufrimiento en el NT", Senderos, 34 (1989) 15-24.

MARTINS TERRA, João "O misterio da pascua”, Actualizaçao, 23 (1991) 151-162.

MARTINS TERRA, João "Filosofías subyacentes a moderna Cristología Latinoamericana", Actualização, 157/158 (1983) 19; CELAM Cristo el Señor, 1984, 281-349.

MARTINS TERRA, João "El sofrimento na Sagrada Escritura para una teología de la Cruz", Actualização, 183-184 (1985) 113-138.

MARTINS TERRA, João "Jesús catequeta e evangelista", Revista de cultura bíblica, VI/ 23-24 (1982) 20- 42.

MASI, Nicolau “Cristo, o obediente desobediente", Estudios bíblicos, 6 (1985) 53-64.

MASI, Nicolau "O papel das mulheres na vida de Jesus", Grande Sinal, 47 (1993) 7-14.

MASIA, Juan "El rostro de Buda y las huellas de Cristo", Sal Terrae, 78 (1990) 549-558.

MAZA, Enrique “Jesús y la institución”, Christus, 480 (1975) 34-38.

MAZA, Enrique "La situación social de México y de la Iglesia ante Jesucristo y ante los pobres", Christus, 425 (1971) 4-5

MAZA, Enrique "Y tú ¿quién dices que es el Hijo del Hombre?", Christus, 481 (1975) 32-42.

MAZAROLLI, Isidoro “O processo de Jesús”, Teocomunicação, 77 (1987) 88-96.

MEEKING, Basil "El evangelio de la salvación”, Boletín teológico, 30 (1988) 127-138.

MEINVIELLE, Juan Carlos "La venida de Jesús: significado actual de la Encarnación”, Didascalia, 378 (1984) 4.

MEIS, Anneliese "De Jesús a las antropologías", Teología y Vida, 34 (1993) 39-60.

MEIS, Anneliese "La preeminencia de Jesús: interrelación filosófico-teológica en la obra de Orígenes", Teología y Vida, 33 (1992) 65-80.

MEJÍA, Jorge "Cristología de algunos autores latinoamericanos" Medellín, 38 (1984) 176.

MEJÍA, Jorge “'Jesucristo el libertador' de Leonardo Boff”, Criterio, 1746 (1976) 456-462. 
MEJÍA, Jorge "Una nueva cristología latinoamericana”, Documentación CELAM, II/12-13, (1977-1978) 1383-1396.

MÉNDEZ, Guillermo "El Jesús histórico según 1Jn”, Boletín teológico, 25 (1987) 21-33.

MÉNDEZ, Víctor "Siguiendo a Jesús pobre”, Fe y solidaridad, 57 (1986) 13-23.

MENDIZÁBAL, Luis M. "El corazón de Jesús en la vida y enseñanza de Juan Pablo II", Tierra Nueva, 68 (1989) 79-86.

MENDOZA DE LA MORA, José "La conversión en el mensaje de Jesús", Christus, 450 (1973) 25-26.

MENÉNDEZ, Valentín "Pro seguimiento de la misión de Jesús. Espiritualidad de los jesuitas asesinados", Sal Terrae, 917 (1989) 875-888.

MESA, Ricardo "Jesús, Hijo de Dios. La divinidad de Nuestro Señor Jesucristo demostrada por los escritos del Nuevo Testamento", Revista Católica, 702 (1931) 563-569.

MESTERS, Carlos "La práctica evangelizadora de Jesús revelada en los evangelios", Ribla, 12 (1992) 9-26.

MESTERS, Carlos "Los profetas Juan y Jesús y otros líderes populares de aquella época”, Ribla, 1 (1989) 49-58.

MESTERS, Carlos “La práctica liberadora de Jesús”, Christus, 597-598 (1986) 87-93.

MESTERS, Carlos "Resurrección y nueva evangelización”, Solidaridad, 121 (1991) 23-26.

MEXIA, Manuel "La presencia de Cristo en la eucaristía", Christus, 445 (1972) 19-22.

MIER, Sebastián S.J. "Cristo Jesús y nuestra fe”, Christus, 429 (1971) 31-32.

MONDRAGÓN, José Luis "La memoria del crucificado", Testimonio, 125 (1991) 22-30.

MONTES, Fernando "Preguntas de Jesús: ¿dónde están los otros nueve?", Mensaje, 409 (1992) 192.

MOREIRA, Vilma "Seguir a Jesucristo", Christus, 578 (1984) 9.

MOREIRA, Vilma "Seguir a Jesús Cristo, noge na America latina exigencia evangélica”, Convergencia out, 176 (1984) 465.

MORENO, Juan Manuel Martín "La experiencia del Resucitado: una experiencia que desencadena la vida”, Diakonía 8/49 (1989) 31-44.

MORIN, Alfredo "Los zelotas y la muerte de Jesús", Medellín, 14/54 (1988) 243-252.

MUNGIA, Víctor Hugo, "La Cristología de 'ser cristianos'. Exposición crítica de algunos aspectos Cristológicos de la obra de Küng”, Senderos, 2/4 (1979) 129-147.

MUÑOZ, Ronaldo "El evangelio de Jesús y el mensaje de la Comunidad apostólica”, Tópicos '90, 3 (1991) 59-62.

MUÑOZ VEGA, Claudio Card. Arz. de Quito "La declaración Cristológica de la conferencia de Puebla", Documentación CELAM, 21, 963-974.

NAJLIS, Michele "El sermón del monte: ¿una doctrina anacrónica a fines del siglo XX?", Xilotl, 5/10 (1992) 9-18.

NAVARRO SANTOS, Jesús "La imagen del Dios cristiano", Paraquaría theológica, 1(1987) 67-104. 
NAVEILLÁN, María Angélica "La novedad de la Encarnación”, Testimonio, 117 (1990) 15-29.

NAVARRO RIZO, Argentina “La resurrección en Pablo", Xilotl 4 (1991) 31- 42.

NOEMI, Juan "Jesucristo como futuro y presente de nuestra historia", Carisma, 29 (1991) 81-90.

NOEMI, Juan "El significado de Mt 25, 40 y 45", Anales de la Facultad de Teología, 19/2 (1967) 1-19.

NOVOA, Laurentino "La cruz de Jesús continúa en la cruz de los hombres", Senderos, 34 (1989) 46-65.

NOVOA PASCUAL, Laurentino "La cruz de Cristo vivida hoy en la cruz de los hombres", Christus, 583-584 (1985) 44-52.

NÚÑEZ s.j., Enrique "El acontecimiento de la cruz en la predicación misionera de San Pablo", Christus, 449 (1973) 24-31.

NÚÑEZ s.j., Enrique "La salvación en el kerigma primitivo", Christus, 455 (1973) 29-31.

OCHAGAVÍA LARRAÍN, Juan s.j. "Fe en Cristo y fe en el hombre", Mensaje, 152 (1966) 428-434.

OCHAGAVÍA LARRAÍN, Juan s.j. "Liberación de Cristo y cambios de estructuras", Mensaje, 188 (1970) 181-188.

OCHAGAVÍA LARRAÍN, Juan s.j. "El poder de Cristo", Teología y Vida, XX/ 4 (1979) 295-308.

O’DONNELL, J. “Trinidad y Cruz”, Boletín de espiritualidad, 116 (1989) 1-9.

OLIVEROS MAQUEO, Roberto "El seguimiento de Cristo hoy en la Vida Religiosa", Puebla, 16 (1982) 42.

ORIOL TUÑI, José “Amar como Jesús. Sentido del mandamiento del amor en el cuarto evangelio”, Diakonía, 10 (1986) 277-289.

ORIOL TUÑI, José "Jesús de Nazaret, criterio de identidad cristiana en el Nuevo Testamento", Diakonía 10/39 (1986) 223-244.

ORIOL TUÑI, José "Pablo y Jesús. La vida de Jesús y la vida de Pablo", Revista Latinoamericana de Teología, 5 (1988) 285-306.

ORIOL TUÑI, José "Jesús en la Carta a los Hebreos", Revista Latinoamericana de Teología, 3/9 (1987) 283 -302.

ORTEGA, Ofelia "Tres parábolas de Jesús sobre pobreza y justicia", Cristianismo y Sociedad, 18/63 (1980) 121-128.

ORTEGA, Rafael c.m. “¿El subversivo de Nazaret?”, Medellín, V (1979) 27-45.

ORTIZ, Eduardo "Cristología latinoamericana”, SIC, XLVI/ 455 (1983) 212.

ORTIZ, Eduardo "Un texto desconcertante. Jesús y los pobres", SIC, XLIII (1980) 306-310.

ORTIZ, Pedro "Jesucristo es el mismo ayer, hoy y lo será siempre. Estudio Exegético”, Theologica Xaveriana, 104 (1992) 441-453.

OSSANDÓN V, Juan Carlos "Jesús, la segunda persona de la Santísima Trinidad", Horizontes, 54 (1984) 71-78.

OVIEDO CAVADA, Carlos “Qué haría Cristo si estuviera en mi lugar?”, Iglesia de Santiago, 291 (1981), Separata.

OVIEDO CAVADA, Carlos "Resurrección y Reconciliación”, Iglesia de Santiago, 29 (1991), Separata 4. 
OVIEDO CAVADA, Carlos "El Señor Resucitado”, Iglesia de Santiago, 29 (1991), Separata 4.

PADILLA C. René "Cristo y Anticristo en la proclamación", Pastoralia 2 (1980) 80-97.

PADILLA C. René "Hacia una cristología Evangélica contextual”, Boletín teológico, $20 / 30$ (1988) 87-102.

PAGURA, Federico "Con Cristo, fuera de las murallas", Actualidad Pastoral 21/175 (1988) 260-264.

PALACIO, Carlos “O Jesús histórico e a Cristología Sistemática”, Perspectiva teológica XVI/4 (1984) 303.

PALACIO, Carlos "Os 'misterios' da vida de Cristo nos", Exercicios Espirituais Itaici 8 (1992) 26-42.

PALUDO, Faustino "Cristo, luz e alimento dos povos", Convergencia 28/264 (1993) 365-376.

PASTOR, Angélica "La praxis mesiánica de Jesús hoy. Compromiso de las religiosas de España", Vida Religiosa, 63/12 (1987) 376-379.

PASTOR, Federico "Cristo solidario: aportación desde San Pablo a la Teología de la Liberación”, Revista Latinoamericana de Teología, 5/14 (1988) 145-162.

PAVEZ, Jorge "Jesucristo y la violencia”, Mensaje, 14/136 (1965) 16-22.

PERDIA, Mateo "El Resucitado es el crucificado", CLAR XXII/8 (1984)4; Christus 583/584 (1985) 29-32; Senderos 31 (1988) 3-11; Testimonio 125 (1991) 44-50.

PÉREZ COTAPOS, Eduardo "Jesucristo, Señor de Reino", Testimonio 135 (1993) 28-34.

PÉREZ, Carlos “Mi Cristo obrero”, Servicio 63 (1982) 6.

PÉREZ, Luis “Jesucristo es Dios”, Revista Católica 47/554 (1924) 360-363.

PIETRANTONIO, Ricardo "El Mesías asesinado: el Mesías Ben Efraín en el evangelio de Juan", Revista Bíblica 44/5 (1982) 1.

PIETRAS, Henry "Cristología Alejandrina en el S.III: Clemente y Orígenes", Medellín 15/58-59 (1989) 229-270.

PIKAZA, Xavier "Jesús y la Vida Religiosa”, Testimonio 119 (1990) 5-9.

PIRONIO, Eduardo Cardenal "Seguir a Jesús resucitado", Revista Vida Espiritual 97 (1989) 53-60.

PIRONIO, Eduardo Cardenal "El Cristo de hoy: el sacerdote", Trípode 8/85 (1971) 12-14.

PIRONIO, Eduardo Cardenal "La liberación que nos trae Cristo", Docla 1-2 (1973) 1.

PIXLEY, Jorge "Jesús y el siervo de Yahveh en el deutero Isaías" Servir XVI/ 85 (1980) 11-47.

POLANCO, Rodrigo "Panorama de la cristología en 40 años de Teología y Vida", Teología y Vida, vol. XLI, 3-4 (2000) 426-474.

POZO, Cándido "La reparación al Corazón de Cristo y las nuevas tendencias cristológicas", Tierra Nueva VIII/29 (1979) 73.

QUINN, Albano. "La cruz del Señor y la cruz del Pueblo sur-andino”, Pastoral Andina, 72 (1990) 27-28.

RAMÍREZ, Alberto “Jesucristo el Señor, el Hijo de Dios es nuestro Salvador", Medellín, 25 (1982) 36. 
RAMÍREZ, Dagoberto "Dones y misterios. La comunidad cristiana cuerpo de Cristo", Pastoral Popular, 210 (1991) 37.

RAMÍREZ, Dagoberto "El Espíritu en los tiempos de Cristo", Pastoral Popular, 42/209 (1991) 37-39.

RAMÍREZ, Dagoberto “La Pasión del Mesías”, Pastoral Popular, 216 (1992) 36-38.

RAMÍREZ, Dagoberto “QQuiénes mataron a Jesús?”, Teología en Comunidad, 2 (1988) 6-8.

RAMÍREZ, Néstor Giraldo "El problema de Jesús histórico", Medellín, Volumen X (1984) 14.

RATZINGER, Joseph "Jesucristo hoy día”, Communio (Santiago), 21 (1990) 5-18.

RATZINGER, Joseph “Orientaciones Cristológicas”, Medellín, X (1984) 3.

REGAN, Patrick "Encuentro con Cristo en la oración común" Cuadernos Monásticos, 70/71 (1984) 343-352.

REGAN, Patrick "Encuentro con Cristo en la oración común", Cuadernos Monásticos, 76 (1986) 85-96.

RENARD, Bruno "La bendición en los primeros siglos cristianos", Nuevo Mundo, 153 (1991) 451-464.

RICCIARDI, Alberto "El elegido / Hijo del hombre, vindicador de los oprimidos”, Revista Bíblica, 44/8 (1982) 4-207.

RIGOL, P.N. "Cristología popular: alienación o ironía”, Cristianismo y Sociedad, 13 (1975) 29-34.

RIQUELME, Julián "En las huellas de Cristo Orante", Testimonio, 111 (1989) 99.

RIQUELME, Julián "Jesucristo asume y transforma la cultura de su pueblo", Testimonio, 135 (1993) 68-80.

RIQUELME, Julián "En la voluntad de Jesús palpita la fuerza de Dios”, Testimonio, 112 (1989) 5-9.

RITCHIE, Nelly "Mujer y Cristología”, Cuadernos de Teología, 7/3 (1986) 141- 152 .

ROCHA, Mateus “O seguimiento de Jesús Cristo”, Convergencia, 192 (1986) 242-251; Reb. Fas., 165 (1982) 12.

RODRÍGUEZ, Hilario "Jesús y los grupos”, Nuevo Mundo, 89/90 (1979) 435-446.

ROS, Salvador "Jesús en el marxismo humanista", Revista de Espiritualidad, 17/186 (1988) 121-166.

ROSAS, Jenaro “Jesús, el Reino, la Iglesia” Christus, 562 (1983) 18- 20.

ROVIRA BELLOSO J.M. "Cuál es el sentido de Jesús de Nazaret" Diakonía, VI/23 (1982) 66.

RUSKAMP, Florian ofm "Testimonio de la tercera presencia de Cristo en América Latina", Cuadernos Franciscanos de Renovación, 10 (1970) 137-139.

S/A “Jesús Murió, Cristo Resucitó. Meditación sobre el hombre y sobre Dios”, Mensaje, 24 (1975) 78-83.

S/A “Jesús, el Reino y los Pobres”, Christus (Cuaderno Especial), 45 (1980) $15-47$

S/A "La muerte de Jesús y la liberación”, Christus (cuaderno especial), 42/496 (1977)12-33.

SAHADE, Ignacio "Pascua de Resurrección en nosotros hoy", Estudios Ecuménicos, 4 (1983) 15. 
SÄHLI, Pablo "La pascua de Jesucristo y la luz de la vida", Mensaje, 29/292 (1980) 463-468.

SALAS, Antonio "Justicia y Reino. El mensaje social de Jesús", Biblia y Fe, 17/50 (1991) 50-81.

SALINAS, Maximilano "En los orígenes del movimiento obrero: El Cristo de los pobres", Pastoral Popular, $39 / 187$ (1988) 32.

SALINAS, Maximiliano "Don Enrique Alvear: la solidaridad como unión mística entre Jesús y los pobres", Mensaje, 421(1993) 350-352.

SALTZMAN, Daniela C. "Jesús. Deseos de los callados eternos", Cuadernos Monásticos, 16/58 (1981) 351-353.

SÁNCHEZ, Manuel “Jesucristo centro de la evangelización”, Testimonio, 135 (1993) 14-20.

SÁNCHEZ, José "La estrategia de Jesús al servicio del Reino de Dios", Christus (México), 54/622-623 (1989) 43-50.

SÁNCHEZ, Luis “Jesús de Nazaret, el liberador", Solidaridad, 2/12 (1980) 8-15.

SANFELIÚ, Federico “Acceso a Jesús”, Mensajero, 69/723 (1988) 27-31.

SANTAGADA, Osvaldo "Ecclesia quotidie gignit ecclesiam. El misterio del Corazón de Jesús en la vida religiosa femenina”, Cuadernos Monásticos, 72 (1985) 71-86.

SANTAGADA, Osvaldo "El misterio del Corazón de Jesús y el sacerdocio ministerial", Tierra Nueva, 11/48 (1984) 62.

SANTAGADA, Osvaldo, "Pascua y sacrificio redentor de Jesús", Criterio, 50/ 1760 (1977) 129-134.

SANTAGADA, Osvaldo "Unus Christus Amaris Patrem", Medellín, 10/10 (1984) 55.

SANTECCHIA, Benito "La pascua de Jesús: médula de la fe y del anuncio eclesial”, Didascalia, 41/400 (1987) 5-10.

SANTECCHIA, Benito “¿Resurreccióm, reanimacióm, reencarnación o qué?”, Didascalia, 464 (1993) 17-24.

SANTOS, Carmelo "La cruz de Cristo, fuente de vida Pascual. Perspectivas para una pastoral del dolor", Nuevo Mundo, 16/94 (1980) 357-368.

SARRACO, Norberto "Las opciones liberadoras de Jesús", Nusem, 1/3 (1982) 9.

SASKIA, Osserwaardi "A cruz de Cristo. Uma reflexao historico-religiosa", Estudios Teológicos, $30 / 3$ (1990) 177-186.

SCHEFFCAZYK, Leo "Introducción acerca del tema teológico de los misterios de la vida de Jesús”, Tierra Nueva, 13/50 (1984) 76.

SCHEFFCAZYK, Leo "La devoción a Cristo como medio de la experiencia de Cristo", Tierra Nueva, 10/37 (1981) 72.

SCHEFFCAZYK, Leo "El significado de los misterios de la vida de Jesús para la fe y la vida del cristiano", Tierra Nueva, 13/50 (1984) 83.

SCHEID, Eusebio "Los que sufren contemplando al traspasado. Reflexiones teológico-existenciales", Tierra Nueva, 8/31 (1979) 59-74.

SCHELLEMBAUM, Peter "El fuego transformante del Corazón de Jesús", Tierra Nueva, 9/34 (1980) 85-96.

SCHAEFFER, Darío "Cruz de Pobre: Componentes Anti-útopicos de processo de Exploracão dos pobres” Estudios Teológicos, $30 / 3$ (1990) 187-197. 
SCHILLEBEECKX, E. "Mesianismo. Antimesianismo de Jesús y los mesianismos exclusivamente humanos", Vida Religiosa, 68/5 (1990) 347-350.

SCHMIDT, Matthias "Invenire Christum in Hominibus", Cuadernos Monásti$\cos , 70 / 71$ (1984) 361-370.

SCHNACKENBURG, Rudolf "Y la Palabra se hizo Carne", Communio (Santiago), 2/5 (1983) 29-34; Comunnio (Santiago), 4/16 (1986) 29-36.

SCHÖBORN, Von Christoph "La Resurrección de la Carne según la fe de la Iglesia", Communio (Santiago), $7 / 21$ (1990) 40-52; Communio (Madrid), 12/1 (1990) 3247.

SCHÖKEL, Luis "Las Sandalias del Mesías esposo. Símbolos del Antiguo Testamento como lenguaje del Nuevo Testamento", Cuadernos de Teología, 5/3 (1978) 198-210.

SCHOTTROFF, Luise "El Seguimiento de Jesús y la Cruz", Fe y Solidaridad, 41 (1982) 24-30.

SCHULER, Donaldo “Jesus faz milagres? Uma analise de Jo. 21-22", Estudios Teológicos, 23/1 (1983) 73-78.

SECUNDINO, Castro "El sorprendente Jesús de Marcos", Revista de Espiritualidad, 47/186 (1988) 9-48.

SEDAC, "Nuestra salvación es Cristo", Criterio, 58/1942 (1985) 164-169.

SEGUNDO, Juan Luis "Dios, ¿no interesa o no?”, Perspectivas de diálogo 22 (1968) 44-47.

SEGUNDO, Juan Luis "Padre, Hijo, Espíritu: una historia", Perspectivas de diálogo, 24 (1968) 103-109.

SEGUNDO, Juan Luis "Padre, Hijo, Espíritu: una libertad I", Perspectivas de diálogo 25 (1968) 142-148.

SEGUNDO, Juan Luis "Padre, Hijo, Espíritu: una libertad II", Perspectivas de diálogo 26 (1968) 183-188.

SEGUNDO, Rogelio "Espiritualidad del corazón de Jesús, evaluación y perspectiva", Christus (México), 41/ 645-646 (1991) 66-69.

SEPÚLVEDA, Alfredo "Causas médicas de la muerte de Jesús", Educación Médica U.C., 6 (1988) 99-102.

SICARI, Antonio "El Antiguo Testamento y la progresiva encarnación del Verbo", Communio, $2 / 5$ (1983) 11.

SICARI, Antonio "Eucaristía y Resurrección”, Trípode, 20/197 (1983) 16.

SICRE, José “La infancia de Jesús”, Proyección, 160 (1991) 3-18.

SILVA, Joaquín "El significado de muerte de Jesús: Presentación del problema”, Fe y Solidaridad, 41 (1982) 1-6.

SIERRA, Malú "Ser fiel a Jesucristo”, Mensaje 29/291 (1980) 380-391.

SILVA, Sergio "El evangelio de San Marcos", Cuadernos Universitarios, 2 (1975) 3-46.

SILVA, Sergio “Los Milagros de Jesús”, Revista Católica, 89/1081 (1989) 8-16.

SILVA, Sergio "Los Milagros de Jesús”, Revista Católica, 89/1083 (1989) 185-189.

SILVA, Sergio "Sufrimiento y esperanza: Meditación ante la cruz de Cristo", Mensaje, 248 (1976) $156-163$.

SILVA SANTOS, Benito "A exaltação de Jesús na Cruz segundo o evangelho do João", Actualização, 21/235 (1992) 3 - 21. 
SOARES-PRABHU, Jorge "Jesús y el conflicto", Cuadernos de Espiritualidad Ignaciana, 40 (1986) 2-10.

SOBRINO, Jon "El sentido de morir en Cristo", Estudios Centroamericanos (ECA), 218 (1966) 178-186

SOBRINO, Jon "El Jesús histórico. Crisis y desafío para la fe", Estudios Centroamericanos (ECA) 318 (1975) 201-224.

SOBRINO, Jon "La muerte de Jesús y la liberación en la historia", Estudios Centroamericanos (ECA) 323 (1975) 483-511; Equipo Seladoc, Cristología en América Latina. Materiales, VI, Sígueme, Salamanca, 1984, 43-88.

SOBRINO, Jon "Tesis sobre una cristología histórica", Estudios Centroamericanos (ECA) 323 (1975) 457-482.

SOBRINO, Jon "El Cristo de los Ejercicios", Christus, $40 / 476$ (1975) 44-45.

SOBRINO, Jon "El Jesús Histórico. Crisis y desafío para la fe", Christus, 40/ 481 (1975) 6-18.

SOBRINO, Jon "La fe en Jesús. Relevancia para la cristología y el seguimiento", Christus, 41/484 (1976) 15-39.

SOBRINO, Jon "Cristo una gran noticia”, Diálogo, 31 (1976) 12-17.

SOBRINO, Jon "La oración de Jesús y del cristiano", Christus, 42/500 (1977) 25-48; Selecciones de Teología, 71 (1979) 193-205.

SOBRINO, Jon "Jesús y el Reino de Dios. Significado y objetivos últimos de su vida y misión, Sal Terrae, 780 (1978) 345-364; Christus, 540 (1980) 17-25.

SOBRINO, Jon "La oración de Jesús", Cuadernos de espiritualidad, 7 (1978) 3-20.

SOBRINO, Jon "Cristología en discusión. Panel sobre la cristología desde América Latina”, Christus, 43/511 (1978) 13-21.

SOBRINO, Jon "El seguimiento de Jesús como discernimiento", Concilium, 139 (1978) 517-529; Diakonía, 11 (1979) 16-28.

SOBRINO, Jon "Relación de Jesús con los pobres y desclasados", Concilium 150 (1979) 461-471.

SOBRINO, Jon "La conflictividad de Jesús. Dialogando con Jon Sobrino", Solidaridad, 4 (1979) 41-45.

SOBRINO, Jon “Cristología de Puebla", Páginas, 4/23 (1979) 54-58; Diakonía, 9 (1979) 75-82.

SOBRINO, Jon "Espiritualidade de Jesús e espiritualidade de libertação", REB, 39/156 (1979) 604-615.

SOBRINO, Jon "Reflexiones sobre el documento de Cristología de Puebla", Fe y Solidaridad, 3 (1979) 9; Equipo Seladoc, Puebla, V, Salamanca, 1981, 159-171.

SOBRINO, Jon "Espiritualidad de Jesús y de liberación", Christus, 529/530 (1979/1980) 59-63.

SOBRINO, Jon "Jesús el Reino de Dios. Significado y objetivos últimos de su vida y misión”, Christus, 45/540 (1980) 17-25.

SOBRINO, Jon "La aparición del Dios de la vida en Jesús de Nazaret", en AAVV, La lucha de los dioses, San José, 1980, 79-121.

SOBRINO, Jon "La experiencia de Dios en la Iglesia de los pobres", en AAVV, Apuntes para una teología nicaragüense, San José, DEI-CAV, 1981, 143-176.

SOBRINO, Jon "Dios y los procesos revolucionarios", Christus, 556 (1982) $15-27$. 
SOBRINO, Jon "La fe en el Hijo de Dios desde un pueblo crucificado", Concilium, 173 (1982) 331-340.

SOBRINO, Jon "El resucitado es el crucificado", Sal Terrae, 826 (1982) 181194; Diakonía, 21 (1982) 25-40; Nuevo Mundo, 109 (1983) 7-19.

SOBRINO, Jon "Significado actual del Reino de Dios anunciado por Jesús", Diakonía, $7 / 26$ (1983) 94-110; Iglesia Viva, 105-6 (1983) 361-378.

SOBRINO, Jon "Jesús de Nazaret", en C. Floristán-J.J. Tamayo, Conceptos fundamentales de pastoral, Madrid, 1983, 480-513.

SOBRINO, Jon “Cristologia a partir da América Latina”, Vozes (1983) 217-218.

SOBRINO, Jon "Cómo abordar pastoralmente el tema de Dios", en Fe y Solidaridad (ECO, Santiago de Chile), 44 (1983) 1-31.

SOBRINO, Jon 'Evangelización y seguimiento. La importancia de 'seguir' a Jesús para proseguir su causa", Sal Terrae, 837 (1983) 83-93.

SOBRINO, Jon "Dios", en C. Floristán y J.J. Tamayo (eds.), Conceptos fundamentales de pastoral, Cristiandad, Madrid, 1983, 248-264.

SOBRINO, Jon "Wir sollten Gott Gott sein lassen”, Orientierung 48, N 5 (1984) 53-56.

SOBRINO, Jon "Qué Cristo se descubre en América Latina: hacia una nueva espiritualidad”, Diakonía, 8/29 (1984) 47-67.

SOBRINO, Jon "Dios de vida, urgencia de solidaridad", Misión Abierta 5-6 (1985) 134-149.

SOBRINO, Jon "La centralidad del Reino de Dios en la Teología de la Liberación”, Revista latinoamericana de Teología, $3 / 9$ (1986) 247-282; I. Ellacuría-J. Sobrino, Mysterium Liberationis, Trotta, Madrid, 1990, I, 467-511.

SOBRINO, Jon "Meditación ante el pueblo crucificado", Sal Terrae, 871 (1986) 93-104.

SOBRINO, Jon “La 'teología de la cruz' en el Sínodo”, Sal Terrae, 873 (1986) 257-272.

SOBRINO, Jon "Que Cristo se descobre na América Latina (Em vista a uma nova espiritualidade), Convergencia, 23/213 (1988) 305-318.

SOBRINO, Jon "Jesús como buena noticia. Repercursiones para un talante evangélico", Sal Terrae, 903 (1988) 715-726.

SOBRINO, Jon "La teología de la cruz en el Sínodo de Roma", Senderos, 31 (1988) 36-48.

SOBRINO, Jon "Meditación ante el pueblo crucificado", Diakonía, 49 (1989) 3-16.

SOBRINO, Jon "Cristología sistemática: Jesucristo, mediador absoluto del reino de Dios", en I. Ellacuría-J. Sobrino, Mysterium Liberationis, Trotta, Madrid, 1990, I, 575-599.

SOBRINO, Jon "Es trágico, pero es bello morir como Jesús", Actualidad Pastoral, 23/184 (1990) 179.

SOBRINO, Jon "Cómo predicar la cruz en medio de los crucificados", Testimonio, 125 (1991) 38-43.

SOBRINO, Jon "Los pueblos crucificados, actual siervo sufriente de Yahvé", Christus, 56/644 (1991) 32-37; Páginas, 16 /109 (1991) 73-83; Concilium, 132 (1990) 497-508. 
SOBRINO, Jon "El seguimiento de Jesús pobre y humilde. Cómo bajar de la cruz a los pueblos", Revista Latinoamericana de Teología, $8 / 24$ (1991) 299-318.

SOBRINO, Jon “¿Es Jesús una buena noticia?”, Revista Latinoamericana de Teología, 30 (1993) 293-304; Sal Terrae, 960 (1993) 595-608; Christus, 676 (1994) 34-39.

SOBRINO, Jon "Mesías y mesianismo. Reflexiones desde El Salvador," Concilium, 245 (1993) 159-170.

SOBRINO, Jon “Misereor super turbas ...”, Christus, 662 (1993) 36-38.

SOBRINO, Jon "El espíritu, memoria e imaginación de Jesús en el mundo. 'Supervivencia' y civilización de la pobreza”, Sal Terrae, 966 (1994) 181-196.

SOBRINO, Jon "La fe en el Dios crucificado. Reflexiones desde El Salvador", Revista Latinoamericana de Teología, 31 (1994) 49-75.

SOBRINO, Jon "La pascua de Jesús y la revelación de Dios desde la perspectiva de las víctimas", Sal Terrae, 977 (1995) 205-220; Revista Latinoamericana de Teología, 34 (1995) 79-91.

SOBRINO, Jon “Jesús como eu-aggelion”, Diakonía, 83 (1997) 70-88.

SOBRINO, Jon “'Luz que penetra las almas', espíritu de Dios y seguimiento lúcido de Jesús”, Sal Terrae, 1008 (1998) 3-15.

SOBRINO, Jon “'Jesús y pobres'. Lo meta-paradigmático de las cristologías”, Selecciones de teología 150 (1999) 160-168; Misiones extranjeras (1997) 499-511.

SOBRINO, Jon "La resurrección de Jesús desde las víctimas", Utopías, 62 (1999) 15-17; Selecciones de teología 156 (2000) 259ss.

SOBRINO, Jon "El crucificado", en J.J. Tamayo Acosta (ed.), Diez palabras clave sobre Jesús de Nazaret, Verbo Divino, 2000.

SODANO, Angelo "Encuentro con Cristo", Educación Médica U.C., 6 (1988) 95-98.

SOLER, José "La muerte de Jesucristo, testimonio de su divinidad", Revista Católica, 50/588 (1926) 382-387.

SORIA FLORES, Abraham "Presupuestos antropológicos de una cristología pastoral", Senderos, 1/1 (1978) 41-53.

SOUBLETTE, Gastón “Jesús denigrado por la mafia del cine”, Revista Universitaria, 5 (1981) 43.

SPITAL, Hermann "Jesucristo, redentor de todos los hombres", Yachay, 6/ 9 (1989) 15-24.

STEFANI, Ernesto "Jesús Cristo portador da felicidade", Veritas, 28/109 (1983) 5.

STEFANI, Ernesto "Jesús Cristo revela seu amor aos homens", Veritas, 29/114 (1984) 153-168.

STEFANI, Ernesto, “Jesús Cristo, vida do mundo", Veritas, 30/117 (1985) 1.

STENGER, Silvestre "Al principio era el Verbo. Un ensayo sobre el diálogo humano y divino", Teología y Vida, 2/1 (1961) 31-39.

STORNI, Fernando "A diez años de la Encíclica Redemptor Hominis", Cias, 38/380 (1989) 4-8.

STRADA, Ángel “¿Quién decís que soy yo?, Carisma, 29 (1991) 9-34.

STRIGHINI, Pedro "La cuestión del sacrificio en la epístola a los Hebreos", Ribla, 10 (1991) 91-118. 
SRIGHINI, Pedro "O Reino de Deus e dos pobres", Vida Pastoral, 33/165 (1992) 15-22.

STROTMANN, Norberto "Lo que mueve a Jesucristo", Revista Teológica Limense, 14/1 (1980) 41-66.

STUMME, Juan "Algunas tesis sobre los dos reinos", Cuadernos de Teología, 5/4 (1979) 306-315.

SUÁREZ, María "El Corazón de Cristo", Cuadernos Monásticos, 46/47 (1978) 351.

SUSIN, Luis "Cómo irá Jesús para Santo Domingo", Convergencia, 26/240 (1991) 83-102.

SUSIN, Luis "Jesús, o Cristo e seu projeto político", Teo-Comunicação, 18 /80 (1988) 135-147.

SWANSON, Tod "Cristo y el sentido del tiempo en las tradiciones andinas y amazónicas", Allpanchis, 21/33 (1989) 289-326.

TEPE, Valfredo "Jesús Cristo - A Igreja - O Homen”, Reb, 48/189 (1988) 5-39.

TEPEDINO, Ana María "Jesús e a recuperaçao do ser humano mulher", Reb, 48/190 (1988) 273-282.

TEPEDINO, Ana María "Jesús Cristo: Vida para o mundo e pao para quem tem ome", Grande Sinal 39/6 (1985) 425-434.

TORRE LOPEZ, Salvador "Cristo en San Lucas", Christus 492 (1976) 56-58.

TRAGAN, Ramón “Jesús, Hijo de David - Hijo de Dios", Cuadernos Monásti$\cos$ 70/71 (1984) 333-342.

TRIGO, Pedro "He aquí el hombre”, Sic 47 (1984) 401.

TRIGO, Pedro "Opción preferencial por los pobres. La causa de los pobres / la causa de Cristo", Christus 44/524 (1979) 24-27.

TRIGO, Pedro "Sólo Cristo salva / Cristo viene: dos slogans inoportunos y necesarios", Sic 51 (1988) 26-27.

TRINIDAD, Saúl “Imágenes de Cristo”, Diálogo 31 (1976) 18-32.

TRINIDAD, S. "Cristología-Conquista-Colonización", Cristianismo y Sociedad, 13 (1975) 12-28.

TUTU, Desmond "Lo que Jesús significa para mí”, Misión 6/1 (1987) 17-20.

URIBE, Sergio "El Misterio Pascual de Cristo", Notas de Pastoral Litúrgica 18 (1974) 11-16.

VALENZUELA, Álvaro "Cristo, el único maestro en san Buenaventura", Revista Católica 1060 (1983) 27.

VALLA, Héctor "Cristo y el cristianismo", Didascalia XXXII/5 (1978) 261-346.

VAN CALSTER, Stefaan "Los relatos bíblicos de los milagros. Reflexiones Pastorales Teológicas y Homiléticas”, Communio 11/4-5 (1989) 350-354.

VANDERHOFF, Francisco "Muerte y resurrección de Jesús y práctica de los cristianos", Christus 42/496 (1977) 26-29.

VANHOYE, Alberto "Jesucristo ayer, hoy y siempre, según la carta a los Hebreos", Medellín 18/70 (1992) 161-170.

VANHOYE, Alberto "Los misterios de la Pasión”, Cuadernos de Espiritualidad 21 (1982) 3-11.

VANIER, Jean “Acoger al pobre es acoger a Jesús”, Cuadernos Monásticos 58 (1981) 285 . 
VARGAS, Hernán "Evangelizar con el estilo de Jesús", Testimonio 135 (1993) 81-88.

VARGAS, Augusto "Debemos realizar el programa evangelizador trazado por Jesús”, Vida y Espiritualidad 7/18 (1991) 115-117.

VARGAS Y RUIZ DE SOMOCURCIO, Fernando "Seguimiento social de Cristo", CELAM 226 (1989) 31-51.

VAUGHN, John "Seguimiento de Jesucristo discipulado", Cuadernos Franciscanos 22/86 (1989) 122-133.

VAZ, José “Cristo criteum, hoje, e sempre”, Revista de Cultura Bíblica 15/5960 (1991) 100-102.

VÉLEZ, Jaime "Proclama la fe y el amor a Jesucristo", Vida Pastoral 21/70 (1993) 12-17.

VÉLEZ, Ricardo "Do mesianismo político ao reino da utopia”, Convivun 2 (1995) 172-176.

VERGARA, Alfonso "Los milagros de Cristo a la luz del misterio pascual", Mensaje 8/77 (1959) 58-62.

VERGARA, Alfonso "Momentos de la fe. Reflexiones sobre el encuentro de Jesús y Nicodemo (Jn 3, 1-21)”, Mensaje 227 (1974) 91-96.

VIAN, Óscar "Cuando vengas con tu Reino (Lc 23, 42)", Estudios Teológicos XIX/17 (1982) 157.

VILLAMAÑAN, Adolfo "Las religiones indígenas y la fe en Jesucristo", Sic 43/423 (1980) 117-119.

VILLAMAÑAN, Adolfo “As religiões indígenas e a fe em Jesús Cristo”, Revista de Cultura Bíblica 6/23 (1982) 5.

VILLAMAÑAN, Adolfo "El Salvador esperado", Nuevo Mundo XVIII/107 (1982) 445.

VILLANUEVA, Carlos "El mensaje de Jesús y la literatura apocalíptica”, Revista Bíblica 53/45 (1992) 15-25.

VILLEGAS, Fabio "El pobre, que es Cristo, nuevo caminar de la Iglesia", Documentos para el Diálogo 42 (1991) 29-35.

VILLEGAS, Beltrán "La predicación de Jesús en el evangelio", Cuadernos Universitarios 1 (1975) 8-33.

VILLEGAS, Beltrán "El amor de Dios en Cristo, según san Pablo", Teología y Vida 24/4 (1983) 275.

VILLEGAS, Beltrán “El Dios de Jesucristo”, Mensaje 36/360 (1987) 251-254.

VILLEGAS, Beltrán "Los dos Adanes y el hombre nuevo", Teología y Vida 31/1 (1990) 47-53.

VILLEGAS, Beltrán “El Hombre y Jesús”, Teología y Vida 34/1-2 (1993) 29-38.

VITORIO, Jaldemir "E procurava ver quem era Jesus. Analise do sentido teológico de ver em Lc 19, 1-10”, Perspectiva Teológica 19/47 (1987) 9-26.

VOLKMANN, Martín "Jesús destruiu o templo - a Igreja o reconstruiu", Estudios Teológicos 30/3 (1990) 243-255.

VON RECHNITZ, Alejandro “¿Cómo era la comunidad que Jesús quería?”, Diakonía 13/51 (1989) 269-280.

VON WERZSÄCKER, Carlos Federico "La pregunta por la paz. En Cristo, esperanza para la humanidad”, Actualidad Pastoral 17 (1984) 193. 
YSERN, Juan Luis “Como nuestro Señor”, Remando Juntos 98 (1983) 3.

YUTZIS, Mario Jorge "La cruz de Cristo y el mecanismo victimario según René Girard”, Revista Bíblica Argentina Nueva Época, 1 (1981) 47.

ZAÑRTU, Sergio "Aproximaciones a la cristología de Ignacio de Antioquía”, Teología y Vida, 21 (1980) 115-127.

ZAÑARTU, Sergio "Resumen, impresiones y apreciaciones sobre Jesucristo Liberador de Leonardo Boff. Primeras aproximaciones hacia una teología latinoamericana", Anales-Ilades, 4 (1986) 2-22.

ZANARTU, Sergio "Notas conclusivas a una docencia de cristología bíblica", Teología y Vida, 32 (1991) 221-232.

ZAÑNARTU, Sergio "Perspectiva trinitaria y cristológica de Tertio Millennio Adveniente", En Juan Pablo II, Tertio Millennio Adveniente, Santiago, San Pablo,

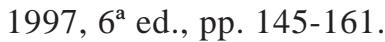

ZAÑARTU, Sergio “Aspectos de la cristología de K. Rahner en Introducción al concepto de cristianismo", Teología y Vida, 38 (1997) 228-244.

ZAÑARTU, Sergio "Reflexiones sobre la fórmula dogmática del Concilio de Calcedonia", Teología y Vida, 39 (1998) 155-184.

ZAÑARTU, Sergio "El Espíritu y el Hijo. Breve reflexión teológica y ecuménica”, Anales de Teología (Universidad Católica de la Santísima Concepción, Concepción) o (1999) 45-54.

ZAÑARTU, Sergio "El Espíritu y el Hijo en la fe de la Iglesia. Algunos alcances respecto a la controversia sobre el Filioque", Teología y Vida, 40 (1999) 278-311.

ZAÑARTU, Sergio "Las naturalezas de las cuales, en las cuales y las cuales es el Cristo", Teología y Vida 29/59 (1992) 21-56.

ZEA, Virgilio "Puebla: Cristología y Liberación”, Theologia Xaveriana 29/51 (1979) 105-116.

ZENTENO, Arnaldo "Del Dios verdugo al Padre liberador. Algunos testimonios de los pobres", Christus 44/519 (1979) 19-24.

ZENTENO, Arnaldo “Tú eres el Dios de los pobres”, Christus 559/560 (1982) 61.

ZILLES, Urbano "Problemas para la cristología hoy", Nuevo Mundo 21/28 (1984) 5-16.

ZILLES, Urbano "Significação teologica da Resurreiçao de Jesus", Теосотиnicação XII/57 (1982) 237.

ZORRILLA, Hugo "Método y función de la cristología hoy", Boletín Teológico $19 / 25$ (1987) 7-19. 